University of Louisville

ThinkIR: The University of Louisville's Institutional Repository

Electronic Theses and Dissertations

$12-2011$

\title{
Thermal analysis of lead zirconate titanate thin films using digital image correlation.
}

Brek J. Meuris

University of Louisville

Follow this and additional works at: https://ir.library.louisville.edu/etd

\section{Recommended Citation}

Meuris, Brek J., "Thermal analysis of lead zirconate titanate thin films using digital image correlation."

(2011). Electronic Theses and Dissertations. Paper 968.

https://doi.org/10.18297/etd/968

This Master's Thesis is brought to you for free and open access by ThinkIR: The University of Louisville's Institutional Repository. It has been accepted for inclusion in Electronic Theses and Dissertations by an authorized administrator of ThinkIR: The University of Louisville's Institutional Repository. This title appears here courtesy of the author, who has retained all other copyrights. For more information, please contact thinkir@louisville.edu. 
THERMAL ANALYSIS OF LEAD ZIRCONATE TITANATE THIN FILMS USING

DIGITAL IMAGE CORRELATION

\author{
By \\ Brek J. Meuris \\ B.S., University of Louisville, 2010

\begin{abstract}
A Thesis
Submitted to the Faculty of the University of Louisville

J.B. Speed School of Engineering as Partial Fulfillment of the Requirements for the Professional Degree
\end{abstract}

\title{
MASTER OF ENGINEERING
}

Department of Mechanical Engineering

December 2011 


\section{THERMAL ANALYSIS OF LEAD ZIRCONATE TITANATE THIN FILMS USING}

DIGITAL IMAGE CORRELATION

Submitted by:

Brek J. Meuris

A Thesis Approved On

(Date)

By the Following Reading and Examination Committee

Dr. Thomas Berfield, Thesis Director

Dr. Zhihui Sun

Dr. Stuart Williams 


\section{ACKNOWLEDGEMENTS}

I would like to thank my thesis advisor, Dr. Berfield, for his guidance through the duration of this thesis. Additionally, I would like to thank Dr. Johnson for all his help with the Fortran code, as well for the use of the J.B Speed School of Engineering servers for DIC computing. I would also like to thank Daniel Porter for his help in the development of the LabView interface that synchronized image capture with the heating

stage. Finally, I would like to thank my family and friends for all of their motivation and support through all stages of my educational journey. 


\begin{abstract}
Lead Zirconate Titanate (PZT), known for its ferroelectric properties, is widely
\end{abstract} used in micro-electromechanical (MEMS) and nano-electromechanical (NEMS) devices. PZT is a ceramic material that is most commonly found in its sol gel form, which allows for a relatively simple and cost-effective means of deposition and device fabrication. The material properties of PZT have been subject to significant research; however, the material properties of PZT sol gels remain largely unknown.

In an effort to further understand thermal strain development, a combination of thermal loading and digital image correlation (DIC) were used to analyze the mechanical response of PZT sol gel films. Additionally, current numerical models are lacking the effects of film adhesion on film failure; therefore, the thermal strain development was analyzed for both well and poorly adhered films. To promote poor adhesion, PZT sol gel films were deposited on a hydrophobic self-assembling monolayer (SAM) and analyzed.

Results indicate that a change in mechanical and optical properties of PZT thin films occurs from $200^{\circ} \mathrm{C}$ to $225^{\circ} \mathrm{C}$. The peak strain associated with this point is approximately $61.4 \%$ greater in 12-layer films than 3-layer films. Sub-cracking of PZT films occurs after island formed during initial film failure experience an area reduction over 30\%. The peak thermal strain development in well adhered 3-layer films is approximately $41.2 \%$ greater than poorly adhered films, indicating that adhesion largely dictates film failure. The 3-layer and 12-layer poorly adhered films fail at temperatures within $2 \%$ percent of each other despite varying surface strain fields, indicating the strain magnitude at the interface drives film failure. 


\section{TABLE OF CONTENTS}

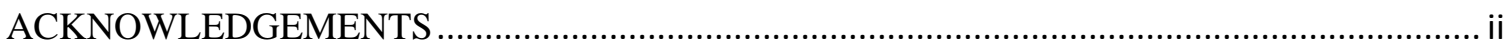

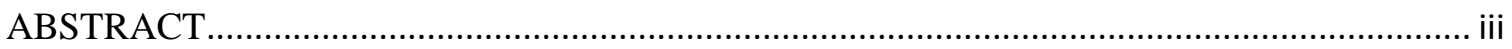

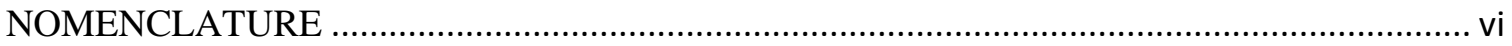

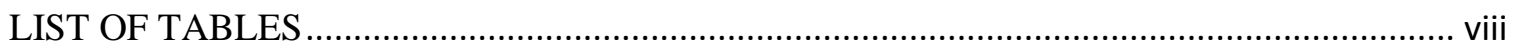

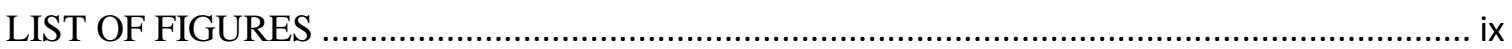

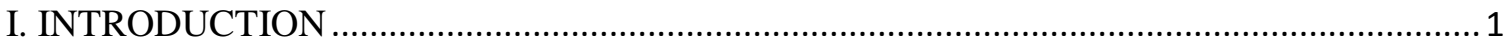

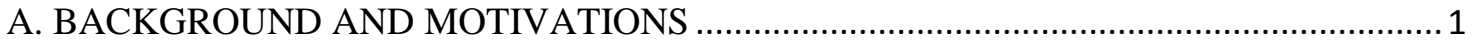

B. MECHANICS OF THIN FILM CRACKING …........................................................... 2

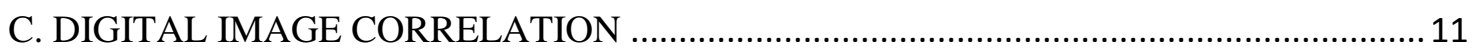

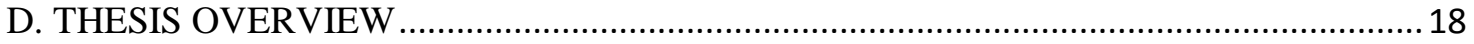

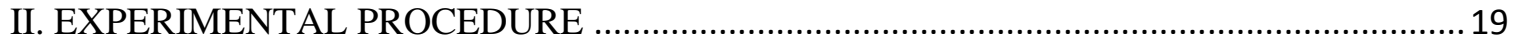

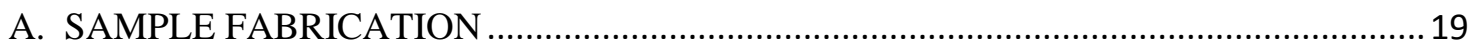

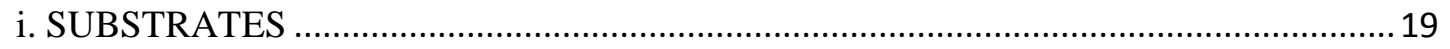

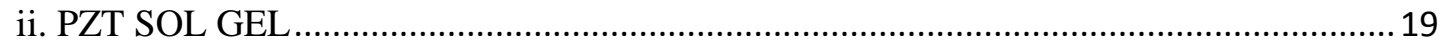

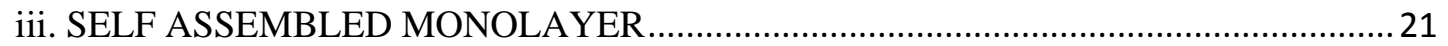

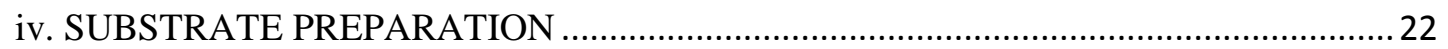

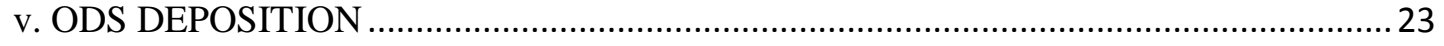

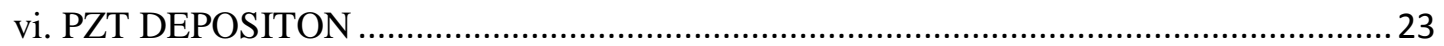

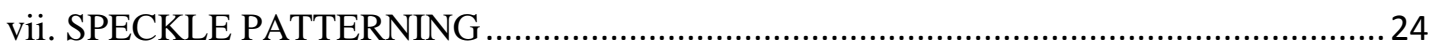

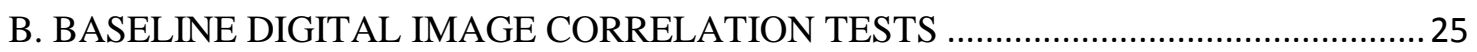

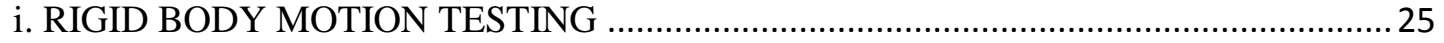

ii. SUBSET SIZE, ITERATIVE PIXEL, AND CORRELATION COEFFICIENT

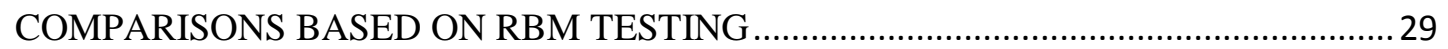

iii. CORRELATION COEFFICIENT OF UTILIZED SPECKLE PATTERN ...................... 30

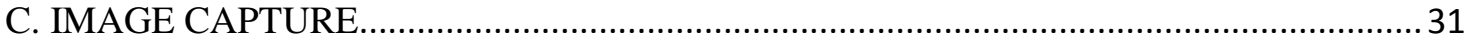

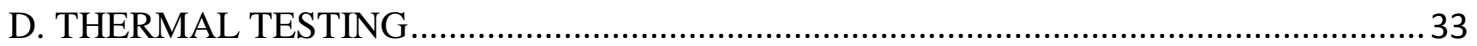

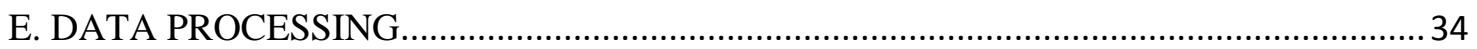

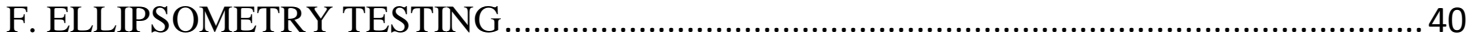

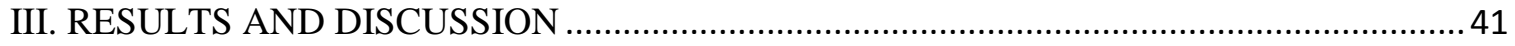

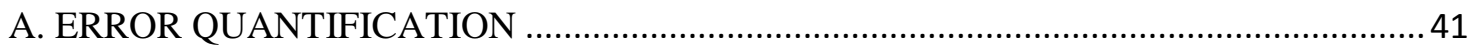


B. THERMAL STRAIN DEVELOPMENT AND FILM CRACKING BEHAVIOR OF

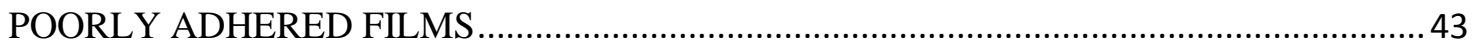

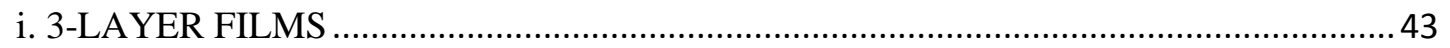

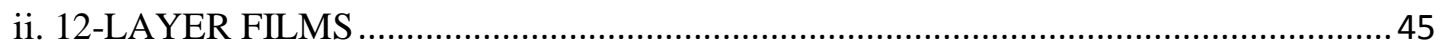

C. PREDICTIONS OF CRACK INITIATION IN POORLY ADHERED FILMS ..................47

D. THERMAL STRAIN DEVELOPMENT IN WELL ADHERED FILMS ..........................50

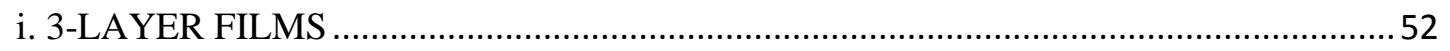

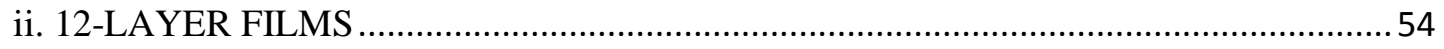

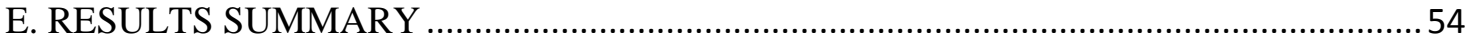

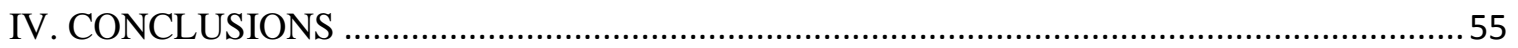

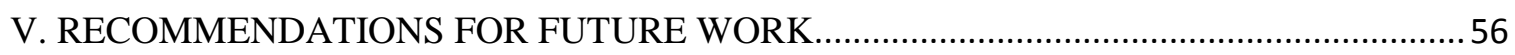

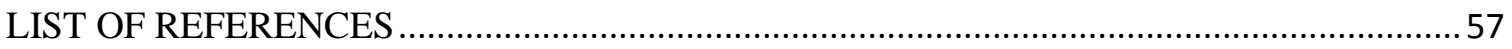




\title{
NOMENCLATURE
}

\author{
$a-$ crack depth \\ $\alpha$-in-plane tensile modulus mismatch \\ $\alpha_{\mathrm{f}}-$ film thermal expansion coefficient \\ $\alpha_{\mathrm{s}}-$ substrate thermal expansion coefficient \\ $\beta$ - in-plane bulk modulus mismatch \\ $\mathrm{CC}$ - correlation coefficient \\ CCs - subpixel correlation coefficient \\ dci - deformed column intensity \\ dri - deformed row intensity \\ $\Delta \alpha$ - thermal expansion coefficient difference \\ $\Delta \mathrm{I}-$ intensity change \\ $\Delta \mathrm{Is}$ - subpixel intensity change \\ $\mathrm{E}_{\mathrm{f}}-$ film elastic modulus \\ $\mathrm{E}_{\mathrm{f}}{ }^{\prime}-$ film in-plane strain tensile modulus \\ $\mathrm{E}_{\mathrm{s}}-$ substrate elastic modulus \\ $\mathrm{E}_{\mathrm{s}}{ }^{\prime}-$ substrate in-plane strain tensile modulus \\ $\varepsilon-$ strain \\ $\varepsilon_{\mathrm{tf}}-$ strain, thin film approximation \\ $\mathrm{G}$ - energy release rate \\ $\mathrm{h}-$ thickness ratio \\ $\mathrm{K}_{\mathrm{I}}-$ Mode I stress intensity factor \\ $\mathrm{K}_{\mathrm{IC}}$ - Mode I crack initiation toughness
}




$$
\begin{aligned}
& \kappa-\text { curvature } \\
& \kappa_{\mathrm{tf}}-\text { curvature, thin film approximation } \\
& \mathrm{m}-\text { biaxial modulus ratio } \\
& \mathrm{M}_{\mathrm{f}} \text { - film biaxial modulus } \\
& \mathrm{M}_{\mathrm{s}} \text { - substrate biaxial modulus } \\
& \mu_{\mathrm{f}}-\text { film shear modulus } \\
& \mu_{\mathrm{s}}-\text { substrate shear modulus } \\
& v_{\mathrm{f}}-\text { film Poisson's ratio } \\
& v_{\mathrm{s}}-\text { substrate Poisson's ratio } \\
& \text { s- stress singularity exponent } \\
& \text { sci - subpixel column intensity } \\
& \text { sri - subpixel row intensity } \\
& \sigma-\text { stress } \\
& \mathrm{T} \text { - temperature change } \\
& \mathrm{t}_{\mathrm{f}}-\text { film thickness } \\
& \mathrm{t}_{\mathrm{s}}-\text { substrate thickness } \\
& \text { UI - undeformed intensity } \\
& \text { uci - undeformed column intensity } \\
& \text { uri - undeformed row intensity }
\end{aligned}
$$




\section{LIST OF TABLES}

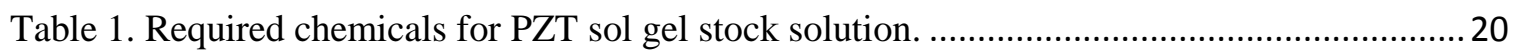

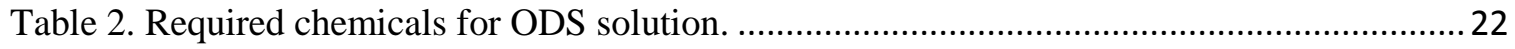

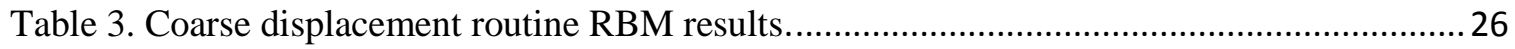

Table 4. Newton Raphson routine RBM results. .................................................................. 26

Table 5. Coarse displacement routine subset and iterative pixel comparison...............................29

Table 6. Newton Raphson routine subset and iterative pixel comparison. .................................. 30

Table 7. Correlation coefficient comparison of various nanoparticle concetrations...................... 31

Table 8. Utilized speckle pattern subset comparison............................................................. 31

Table 9. Initial thicknesses of system components............................................................ 41 


\section{LIST OF FIGURES}

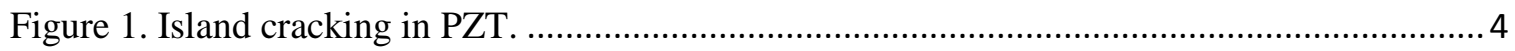

Figure 2. Three modes of crack loading (Mach 2007) .......................................................... 6

Figure 3. (a.) Fully cracked film problem, (b.) Partially cracked film problem (Beuth 1992)....... 7

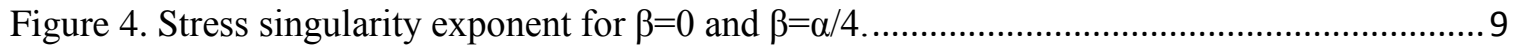

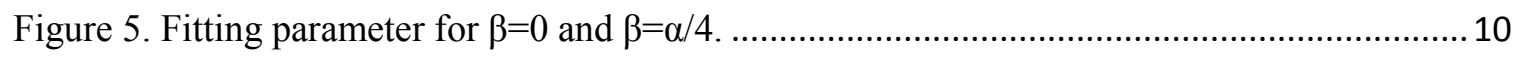

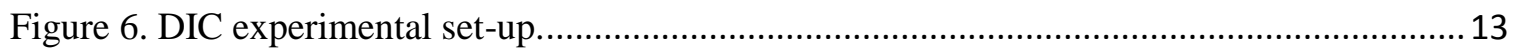

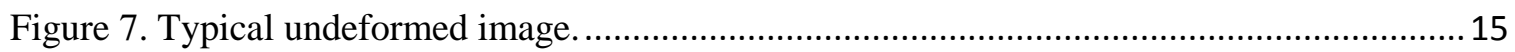

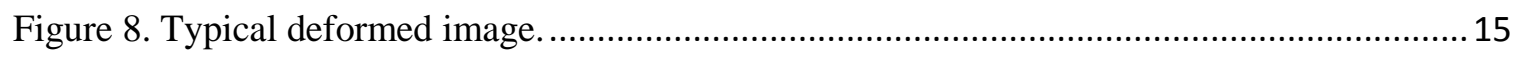

Figure 9. Flow chart for preparation of PZT stock solution. ….............................................. 21

Figure 10. Flow chart for preparation of ODS solution....................................................... 22

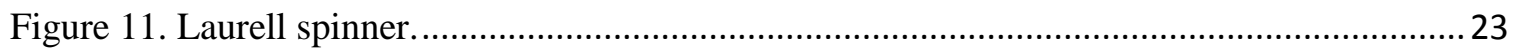

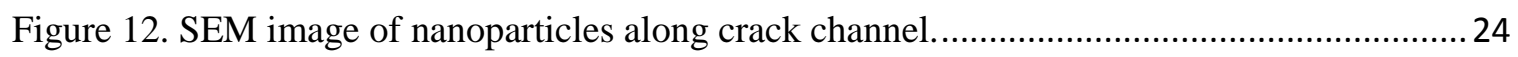

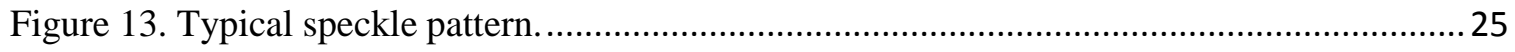

Figure 14. Coarse displacement routine over entire range....................................................... 27

Figure 15. Newton Raphson routine over entire range ....................................................... 27

Figure 16. Coarse displacement routine over reduced range .................................................. 28

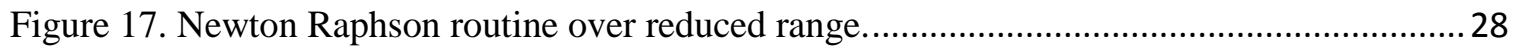

Figure 18. Leica MST49 optical microscope with Retiga-4000R. .......................................... 33

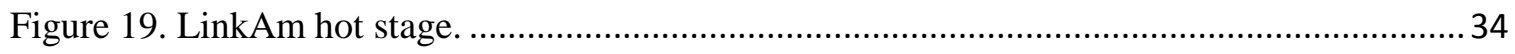

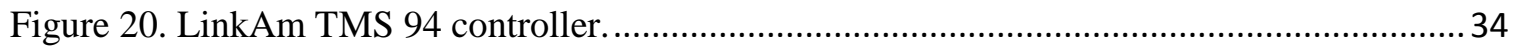

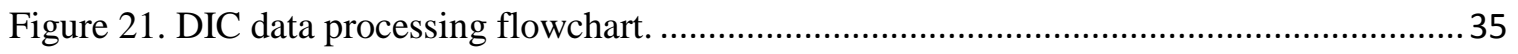

Figure 22. Subset weighting function plotted over the subset intervals. ................................... 37

Figure 23. Measured versus theoretical thermally developed strains in a bare silicon wafer........ 38 
Figure 24. Bare silicon wafer radial displacements at $100^{\circ} \mathrm{C}$.

Figure 25. Bare silicon wafer radial displacements at $200^{\circ} \mathrm{C}$. 39

Figure 26. Bare silicon wafer radial displacements at $300^{\circ} \mathrm{C}$. .39

Figure 27. J.A Woollam WVASE32 ellipsometer............................................................. 40

Figure 28. Steady state $x$ displacements for 60 seconds. .................................................... 42

Figure 29. Steady state $y$ displacements for 60 seconds. ...................................................... 42

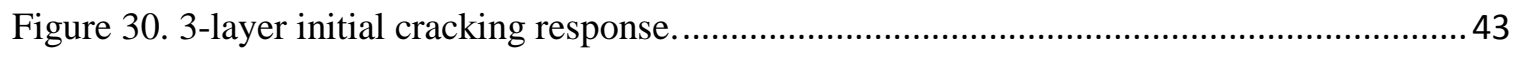

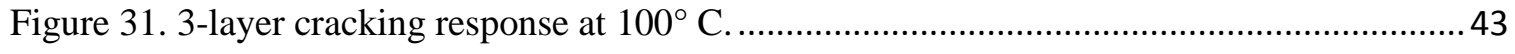

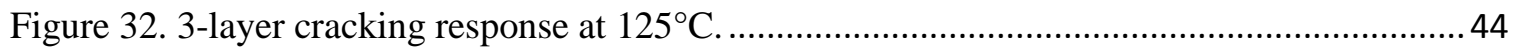

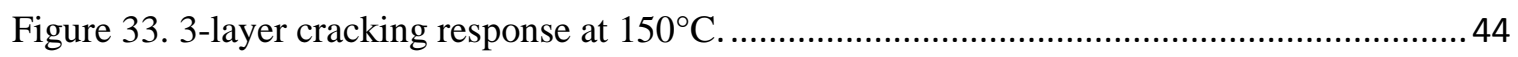

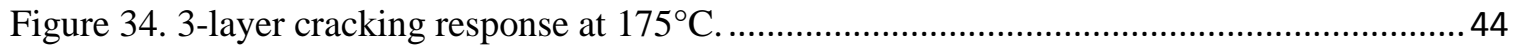

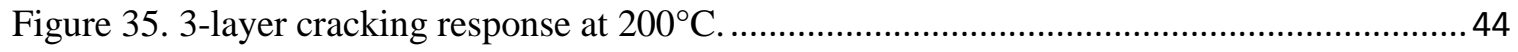

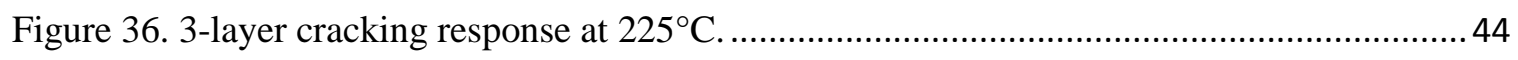

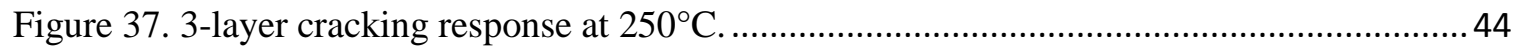

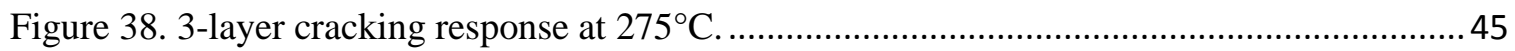

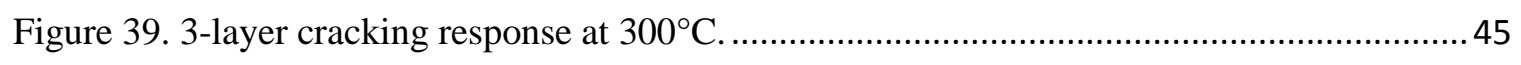

Figure 40. 12-layer initial cracking response ..................................................................... 45

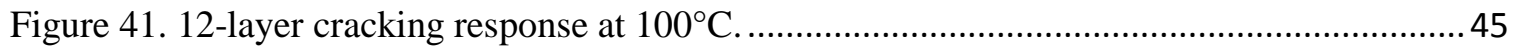

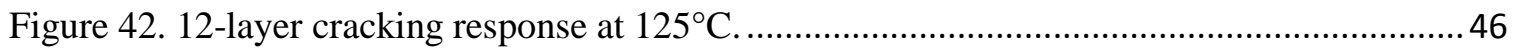

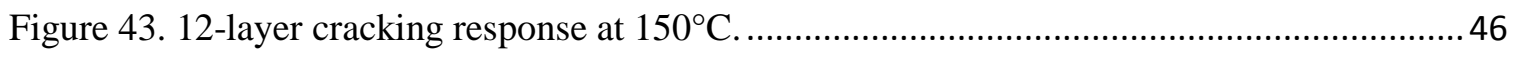

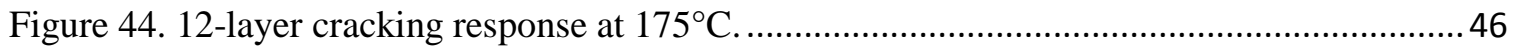

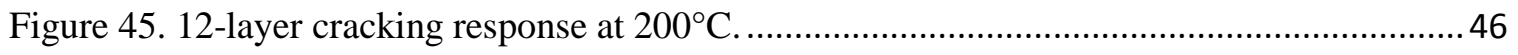

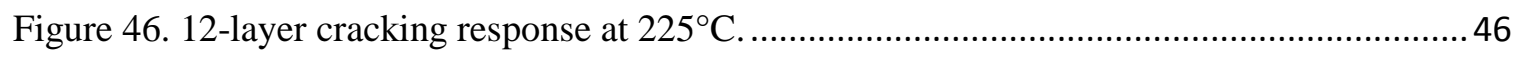

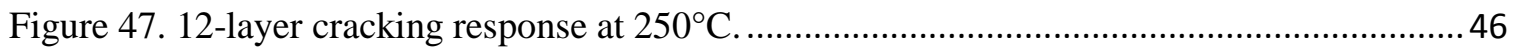


Figure 48. 12-layer cracking response at $275^{\circ} \mathrm{C}$

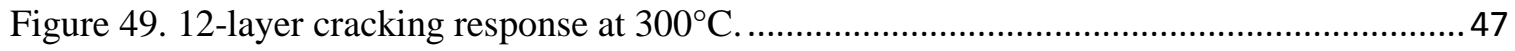

Figure 50. Thermal strain development in poorly adhered films............................................. 47

Figure 51. Island densification in poorly adhered films. ..................................................... 49

Figure 52. Thermal strain development in well adhered films. ................................................ 51

Figure 53. Thermal strain development in well adhered films over reduced range......................52

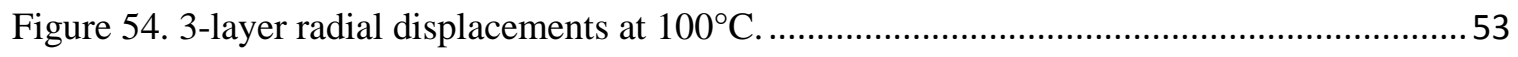

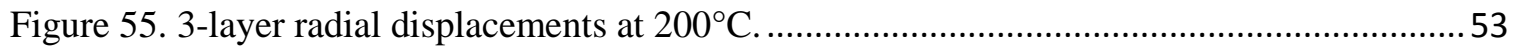

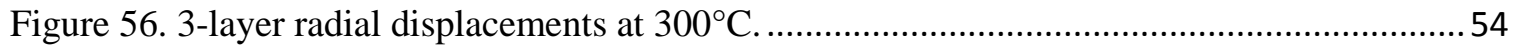




\section{INTRODUCTION}

\section{A. BACKGROUND AND MOTIVATIONS}

Lead zirconate titanate (PZT) plays a critical part in the development of many micro-electromechanical (MEMS) and nano-electromechanical (NEMS) devices. The reason PZT has played such a critical role lies in the fact that it is a very versatile ferroelectric material with excellent piezoelectric properties. Simply stated, when a voltage is applied to a piezoelectric material such as PZT, a mechanical strain is produced. Conversely, when a mechanical strain is applied, a change in electric potential is produced.

Based on this, PZT is a widely used material in actuators, transducers, or virtually any mechanical sensor. PZT sol gels are used for many MEMS and NEMS devices since they allow for easy, low cost, and repeatable layers to be applied to a surface. A sol gel is characterized as a colloidal solution that evolves into a gel once it is deposited on a substrate. Prior to sol gel processing techniques, PZT films were prepared using more costly and intensive techniques such as RF sputtering, electron beam evaporation, and ion beam deposition (Yi 1996).

Since one of the main applications of PZT sol gels is sensor applications, the material properties are of great interest. Micro and nano sensors are precisely calibrated to work within a set range of specifications. However, these sensors are subject to the same overloading, fatigue, and failure problems associated with all material systems. Additionally, minor variations in processing (chemistry, deposition parameters, heating rates, etc.) can dramatically alter the properties of the final PZT films. This thesis 
investigates the strain development and eventual failure of PZT sol gel films associated with thermal loading and the role of adhesion in this process.

Failure in the form of cracking is often observed as an adverse occurrence. However, as we continue to push the limits of modern fabrication techniques, controlled film failure provides new patterning opportunities. This thesis also looks at the cracking response and creating repeatable cracking, as well as island size modifications for future patterning applications.

\section{B. MECHANICS OF THIN FILM CRACKING}

One of the major issues associated with any sol gel solution is the issue of cracking as a result of the film drying and annealing. This thermal processing is necessary for the modification of optical and electrical properties (phase change) but thermal strains can lead to premature film or device failure.

Thin film cracking under thermal loading is also of significant interest because of the prevalence in specialty coatings designed to modify substrate surface properties as in electro-optics (Yi 1996). Many of these thin film coatings are applied to substrates that will be subjected to high thermal loads and if the coating fails, the substrate becomes more prone to failure as well. The analysis of thin film failure is of great interest and has been subject to research by the likes of Xia and Hutchinson (2000), Hutchinson and Suo (1992), and Beuth (1992).

During the heating process to convert the sol gel into a ceramic, the mismatch between the mechanical and thermal properties of the substrate and film, as well as the evaporation of solvents present in the solution often result in film cracking. During the initial drying stage, the film begins to densify and residual strains develop in the film- 
substrate system. Film densification is a result of atmospheric pressure compressing the film and releasing solvents, which reduces the capillary pressure present in the film (Yow et al. 2010). During this same time, solvent present in the system is also evaporating, which increases the capillary pressures present in the film. As the film continues to densify during this process, the adherence to the substrate prevents the film from freely contracting and results in residual stress development in the film.

When films are thermally loaded, this problem is further compounded. During thermal loading, not only is a rapid drying process occurring, but the mismatch in the film-substrate thermal and mechanical properties also have a significant effect on the loading parameters. This combination creates a film that is in a state of drying, densifying, and contracting coupled to a substrate that is linearly expanding due to the applied temperature gradient. The mechanical and thermal mechanics will be discussed further in the following pages.

According to Nakasa (1998), cracks in drying thin films on a robust substrate (i.e. substrate much tougher than the film) fall into three categories: "cobweb type", "island delamination type", and "repeating division type". All three types are characterized by relationship the between the substrate and the thin film.

The "cobweb type" is characterized by a single short crack that originates at the center of the sample and propagates radially, forming branches and circular cracks that then intersect the branched cracks (Nakasa 1998). The substrate-thin film relationship that is typically found where "cobweb" cracks exist is a very brittle thin film adhered to a ductile substrate, which prevents delamination (Nakasa 1998). 
"Repeating division type" cracking is characterized by a cracking pattern that, true to its name, continues to crack into smaller regions until the point of delamination is reached. The substrate-thin film relationship typically associated with "repeating division type" cracking is when the bond strength between the substrate and thin film is very large (Nakasa 1998).

The "island delamination type" cracking (which is of interest for this thesis) is characterized by hexagonal cracking followed by delamination from the substrate (Nakasa 1998). The characterizing parameter of "island delamination" cracking is the low bond strength between the substrate and thin film (Nakasa 1998). Figure 1 shows the island type cracking patterns that occur in the PZT formulation utilized in this thesis.

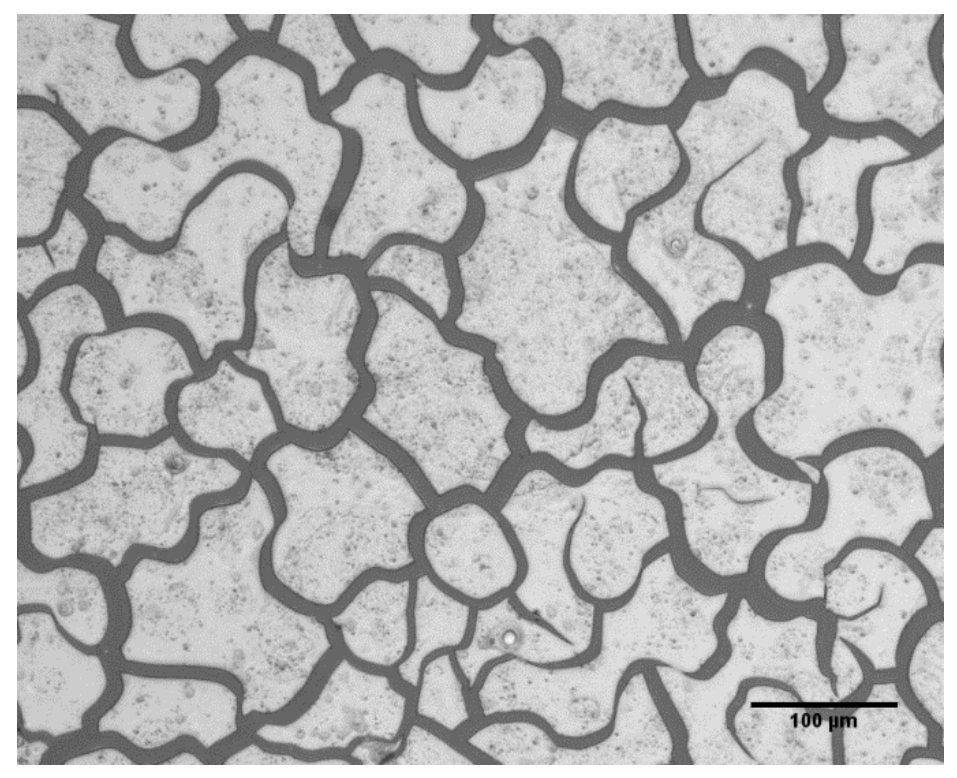

Figure 1. Island cracking in PZT.

Although "island delamination" cracking is the failure form of interest for this thesis, the mechanics of thermal loading which ultimately induce this failure must be discussed further. Research has previously been conducted on an isotropic, bilayer plate 
model, which is a reasonably adequate model for the PZT films presented in this thesis (Bhusan 2004).

The fundamental thermomechanics of the isotropic, two-layer model are helpful to understand the cracking due to thermal loading. The Springer Handbook of Nanotechnology, Bhusan (2004), provides a thorough reference on the isotropic, two layer model. Parameters relating the mechanical properties and physical properties must first be calculated for the thermomechanic analysis. These parameters are:

$$
\begin{gathered}
h=\frac{t_{f}}{t_{s}} \\
m=\frac{\left(\frac{E_{f}}{1-v_{f}}\right)}{\left(\frac{E_{s}}{1-v_{s}}\right)} \\
\Delta \alpha=\alpha_{s}-\alpha_{f}
\end{gathered}
$$

where the subscript $f$ corresponds to the film and $s$ corresponds to the substrate with $t$ being thickness, $E$ the elastic modulus, and $v$ being Poisson's ratio. From these parameters, the curvature and the strain at the interface are calculated using:

$$
\begin{gathered}
\kappa=\frac{6 \Delta \alpha T}{t_{s}} h m\left(\frac{1+h}{1+2 h m\left(2+3 h+2 h^{2}\right)+h^{4} m^{2}}\right) \\
\varepsilon=T\left(\frac{\alpha_{f} m h\left(1+3 h+3 h^{2}+m h^{3}\right)}{1+2 h m\left(2+3 h+2 h^{2}\right)+h^{4} m^{2}}+\frac{\alpha_{s}\left[1+m h\left(3+h+h^{2}\right)\right]}{1+2 h m\left(2+3 h+2 h^{2}\right)+h^{4} m^{2}}\right)
\end{gathered}
$$

where $T$ is the temperature change. In the thin film case $\left(t_{f}<<t_{s}\right)$, Equations IB4 and IB5 can be reduced to:

$$
\begin{gathered}
\kappa_{t f}=\frac{6 \Delta \alpha T}{t_{s}} h m \\
\varepsilon_{t f}=\alpha_{s} T
\end{gathered}
$$


assuming the substrates mechanical properties are dominant. For the PZT thin film system of interest used in this thesis, the thin film approximation is valid.

From Equation IB6 and Equation IB7 the stress distribution across the thickness is calculated using:

$$
\sigma(z)_{f, s}=M_{f, s}\left(\varepsilon+z \kappa-\alpha_{f, s} T\right)
$$

where $\mathrm{M}_{\mathrm{f}, \mathrm{s}}$ is the biaxial modulus. Due to the virtually negligible thickness of the thin film, the stress is often presented in the commonly used wafer curvature method and is written in the form:

$$
\sigma_{f}=\frac{M_{s}}{6} \frac{t_{s}^{2}}{t_{f}} \kappa
$$

The equations presented represent the theoretical limits for the thin film and are based on the assumption of perfect adhesion at the interface and continuous strain across the interface.

In addition to the thermomechanics consideration, a general discussion of fracture mechanics is necessary prior to analyzing the specifics of the thin film failure. In facture mechanics there are three modes of crack loading. Mode I is opening, Mode II is shearing, and Mode III is tearing. The three modes are illustrated in Figure 2.
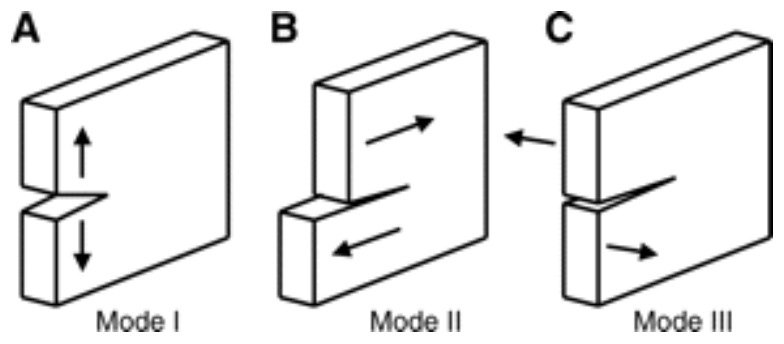

Figure 2. Three modes of crack loading (Mach 2007). 
The main driving factor behind fracture mechanics is the stress intensity factor $\mathrm{K}_{\mathrm{I}}$, which is defined as:

$$
K_{I}=\lim _{y \rightarrow 0}\left(\sqrt{2 \pi y \sigma_{x x}}\right)
$$

where I indicates the first mode of crack loading, (Dally 2005), which encompasses all fracture present in this thesis. Plane strain fracture occurs when:

$$
K_{I} \geq K_{I C}
$$

where $\mathrm{K}_{\mathrm{IC}}$ is the crack initiation toughness.

Previous research performed by Beuth (1992) breaks traditional film cracking into fully and partially cracked film problems based on whether or not the crack propagates to the surface of the substrate. Figure 3 illustrates the difference between the fully and the partially cracked film problem.

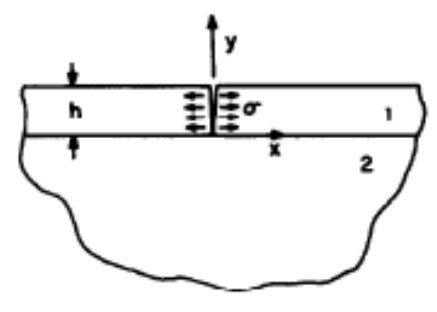

(a)

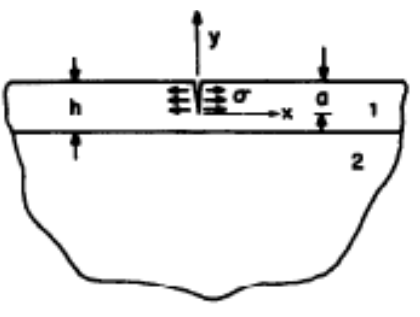

(b)

Figure 3. (a.) Fully cracked film problem, (b.) Partially cracked film problem (Beuth 1992).

Beuth (1992) proposed a numerical solution that approximates a solution for the cracked film problem. Thin film mechanics utilized the previously discussed thermomechanical and fracture mechanics principles and has developed two dimensionless material dependent properties referred to as the Dundurs parameters, $\alpha$ and $\beta . \alpha$ is the mismatch between the in-plane tensile modulus across the interface and $\beta$ is 
the mismatch between the in-plane bulk modulus. The Dundurs parameters are defined as:

$$
\begin{gathered}
\alpha=\frac{E_{f}^{\prime}-E_{s}^{\prime}}{E_{f}^{\prime}+E_{s}^{\prime}} \\
E_{f, s}^{\prime}=\frac{E_{f, s}}{\left(1-v_{f, s}^{2}\right)} \\
\beta=\frac{1}{2} \frac{\mu_{f}\left(1-2 v_{s}\right)-\mu_{s}\left(1-2 v_{f}\right)}{\mu_{f}\left(1-v_{s}\right)+\mu_{s}\left(1-v_{f}\right)} \\
\mu_{f, s}=\frac{E_{f, s}}{2\left(1+v_{f, s}\right)}
\end{gathered}
$$

where the subscript $f$ denotes the film and $s$ denotes the substrate (Beuth 1992). For most material combinations, $\beta$ lies in the range of $\beta=0$ and $\beta=\alpha / 4$, where $\alpha$ has a greater influence than $\beta$ in terms of the Dundurs parameters (Beuth 1992). The $\beta$ bounds of 0 and $\alpha / 4$ are based on the case where both material one and material two are incompressible and where Poisson's ratios for both materials is approximately 0.33 .

The Dundurs parameters are related to the fracture mechanics of thin films through the non-dimensional stress singularity exponent originally derived by Zak and Williams (1963). The stress singularity exponent is solved by finding the roots of Equation IB16:

$$
\cos (s \pi)-2 \frac{\alpha-\beta}{1-\beta}(1-s)^{2}+\frac{\alpha-\beta^{2}}{1-\beta^{2}}=0
$$

where $s$ is the stress singularity exponent. Figure 4 shows the stress singularity exponent plotted over the range of $\alpha$ for $\beta=0$ and $\beta=\alpha / 4$. 


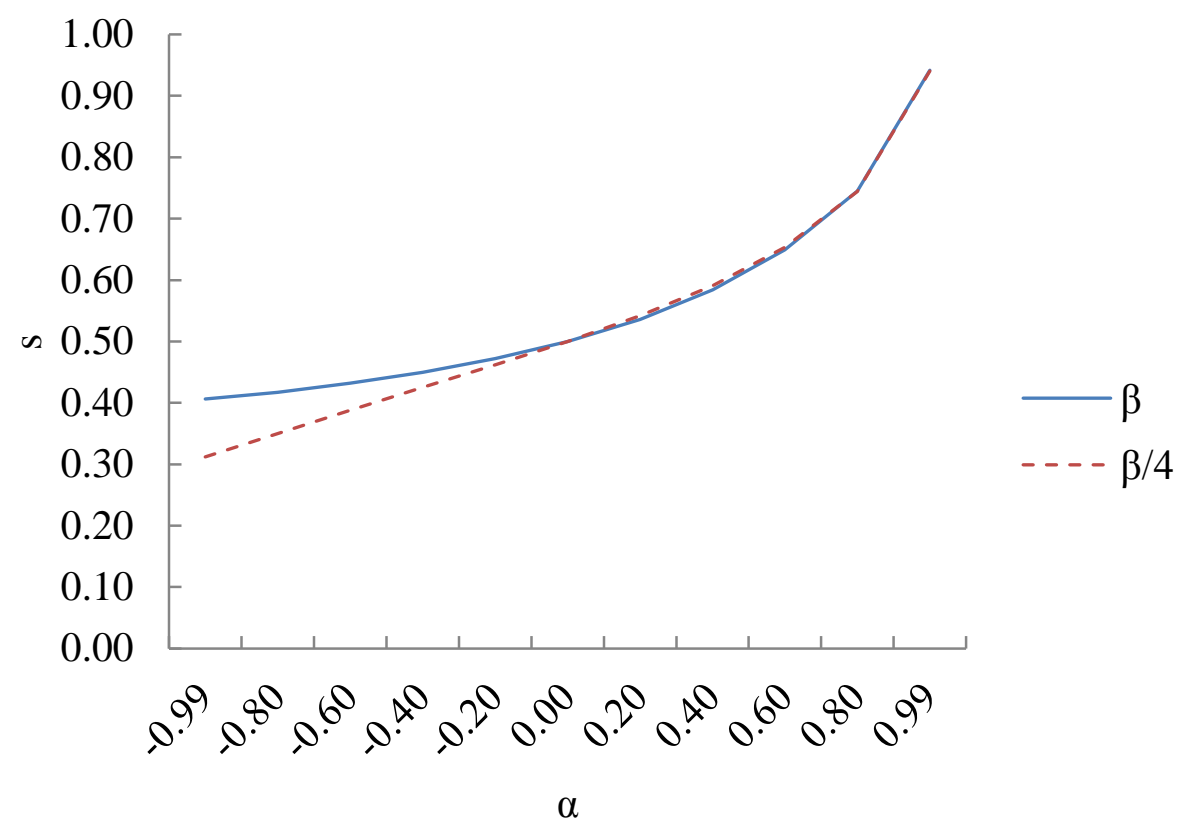

Figure 4. Stress singularity exponent for $\beta=0$ and $\beta=\alpha / 4$.

Beuth (1992) then defined a non-dimensional fitting parameter, $\lambda$, whose purpose is to improve the numerical approximation by fitting the solution near the case of $a / t_{s}=1$ where $a$ is the crack depth and $t_{s}$ is substituted for the film thickness $h$, as shown in Figure 3. Figure 5 shows the fitting parameter plotted over the range of $\alpha$ for $\beta=0$ and $\beta=\alpha / 4$. 


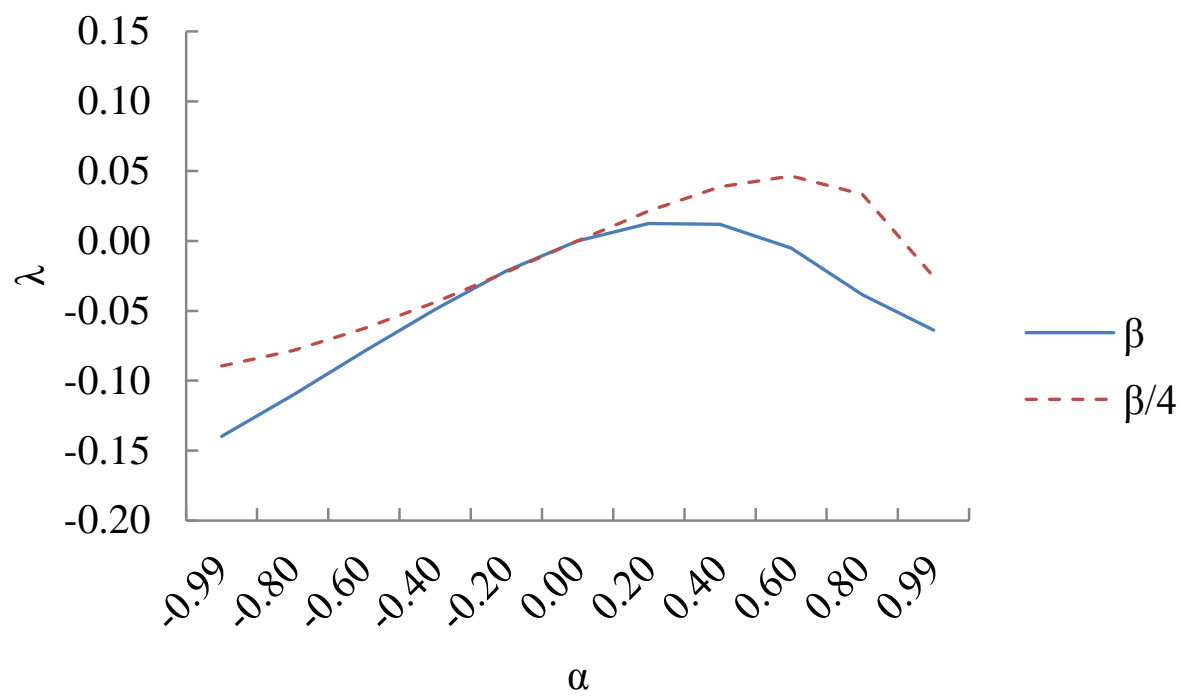

Figure 5. Fitting parameter for $\beta=0$ and $\beta=\alpha / 4$.

From the Dundurs parameters, stress singularity exponent, and fitting parameter, the non-dimensional mode I stress intensity factor is then defined as:

$$
\frac{K_{I}}{\sigma \sqrt{\pi t_{s}}}=1.1215\left(\frac{a}{t_{s}}\right)^{0.5}\left(1-\frac{a}{t_{s}}\right)^{0.5-s}\left(1+\lambda \frac{a}{t_{s}}\right)
$$

(Beuth 1992). The energy release rate is then defined as:

$$
G=\frac{Z \sigma^{2} t_{s}}{E_{f}^{\prime}}
$$

where Hutchinson and Suo (1992) define $Z$ as 3.951 for surface cracks and $Z$ as 1.976 for channeling. From the energy release rate, Zhang et al. (2005) defines the crack initiation toughness as:

$$
K_{I C}=\sqrt{E_{f} G}
$$

At this point the film failure criteria could be calculated through the stress from the thermomechanical analysis and the stress intensity factors from the thin film fracture mechanics analysis. However, the mechanical properties needed for this analysis are not 
currently available for PZT sol gels or easily obtained. This thesis attempts to find the failure strain of PZT thin films experimentally, as well as lay the foundation for finding additional mechanical properties of PZT thin films. Also void from all of the theoretical equations presented is the role that adhesion has on the thin film, substrate model. This thesis also attempts to compare the thermal strain development between a poorly and a well adhered PZT thin film system.

\section{DIGITAL IMAGE CORRELATION}

Digital image correlation is an extensively used experimental mechanics method for measuring material deformation in lieu of the more traditional strain gage technique. Traditional foil strain gages are a proven method for measuring strains in macroscale components but quickly become infeasible as the specimen length scale approaches the microscale.

As the microscale is approached, strain gages are no longer a preferred method due to issues with gage placement and adhesion. Strain gages require the use of a strong adhesive to secure the foil strain gage to the sample. Although the adhesive is a nonissue on stiff materials such as steel, aluminum, etc., it is problematic for more compliant materials like gels, foams, or biological materials. For films microns or less in thickness, the adhesive stiffness is no longer negligible and will introduce significant errors into the measurement system. Another limitation to strain gages is the fact that it makes a point measurement of the strain in one direction, making it difficult to measure complex strain fields.

Photoelasticity is another commonly used experimental mechanics technique but also has significant drawbacks in its methodology. Photoelasticity is an optical method 
that utilizes polarizers and a light source to create distinguishable fringe orders for strain measurement. With advancements in photoelastic measurement techniques and the addition of equipment like the null balance compensator, these advancements make obtaining high accuracy strain measurements possible. However, there is still a high level of subjectivity associated with interpretation of the fringe locations with this method. As the sample scale decreases, it is expected that the level of subjectivity will increase.

For micro-scale applications, digital image correlation (DIC) addresses these issues by combining the capabilities of a high-resolution camera with an optical microscope. DIC is a full field, non-contact method and therefore allows for the analysis of specific areas of interest easily from the macroscale to the microscale. Another benefit of DIC is its ability to directly calculate strains and strain cross derivatives, providing measurement of complex strain fields.

DIC was developed in the 1980's at the University of South Carolina and has continued to evolve as optical and computational resources have improved (Pan 2009). Only a few components are required for the implementation of DIC, making it an extremely accessible experimental mechanics technique. DIC at the microscale requires only an image capture system and a computer capable of running the DIC algorithm. The standard experimental set-up is shown in Figure 6.

In recent years, traditional two-dimensional surface measurement DIC techniques have been expanded to allow for DIC deformation measurements in all three dimensions. For 3-D DIC, an additional second camera is aligned with the plane along with the traditional camera located normal to the plane to capture in-plane displacements. The 
analysis presented here focuses solely on the 2-D in-plane case applied to micro-scale thin films using a single camera coupled with an optical microscope.

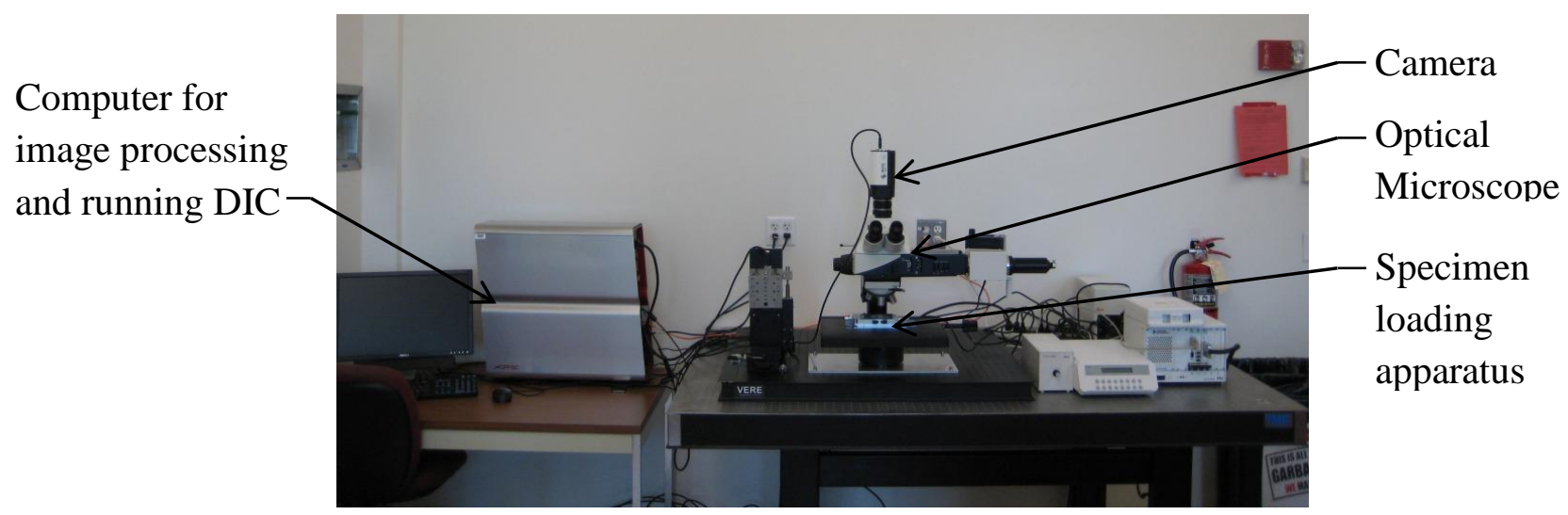

Figure 6. DIC experimental set-up.

The fundamental mechanism of DIC is the correlation of a subset area between images taken of the sample surface prior to and after any type of deformation or thermal loading is applied. DIC utilizes the inherent pixel array that makes up all digital images to perform this correlation. Based on the area of interest, the pixel array is first broken down into subsets. Next, through a DIC algorithm, the respective $u$ and $v$ coordinates of displacement are calculated.

For the DIC algorithm to function, the subset needs to be defined by a distinct pattern, or speckle, as it is commonly referred to in DIC applications. This speckle pattern creates varying pixel intensities across the surface of the material to be tested and allows for a subset to be uniquely defined. From the speckle pattern, the user can then define a subset of interest on the original image by its $x$ and $y$ coordinates and range. The DIC algorithm then tries to correlate this exact subset to the same subset on the second image of interest within a specified range of displacement from its original coordinates. 
The type and size of the speckle pattern has a significant impact on the DIC algorithm and is greatly dependent on the size of the sample. As the samples become larger, so can the speckle pattern and vice-versa. For microscale applications, as presented here, an airbrushed nanoparticle technique is used to speckle the surface with a random pattern that is correlated through the DIC algorithm.

The DIC algorithm is a multistep algorithm with the primary purpose of calculating the displacements between the subset in the undeformed image and the deformed image into the two-dimensional displacement field. These displacements are mapped by taking a point, $p\left(x_{1}, y 1\right)$ and mapping it into $q\left(x_{2}, y 2\right)$ using:

$$
\begin{aligned}
& x_{2}=x_{1}+u\left(x_{1}, y_{1}\right) \\
& y_{2}=y_{1}+v\left(x_{1}, y_{1}\right)
\end{aligned}
$$

where $u$ and $v$ are the $x$ and $y$ displacements (Dally 2005).

The DIC code utilized for this thesis is Fortran code originally developed by the Lambros Group at the University of Illinois. The DIC algorithm utilized has a vast array of functionality but the methodology most relevant to this work is the coarse displacement routine. The coarse displacement routine performs the search function and provides the foundation for all other potential routine options.

In order to run the DIC algorithm, the parameters to be entered are: the gray scale image files for both the deformed and the undeformed image, image size, area of interest, estimated $u$ and $v$ displacement values, subset size, and the iterative pixels between subsets. Significantly undershooting or overshooting the estimated $u$ and $v$ displacement parameters can skew the final results or cause the algorithm to fail prematurely. 
The user-defined number of iterative pixel between subsets and the subset size are also vitally important to the quality of results obtained from the algorithm. The subset size and iterative pixels are dependent on one another but are chosen largely on the speckle pattern and the area of interest. Figure 7 and Figure 8 show several of the key elements to the DIC algorithm on an actual sample image.

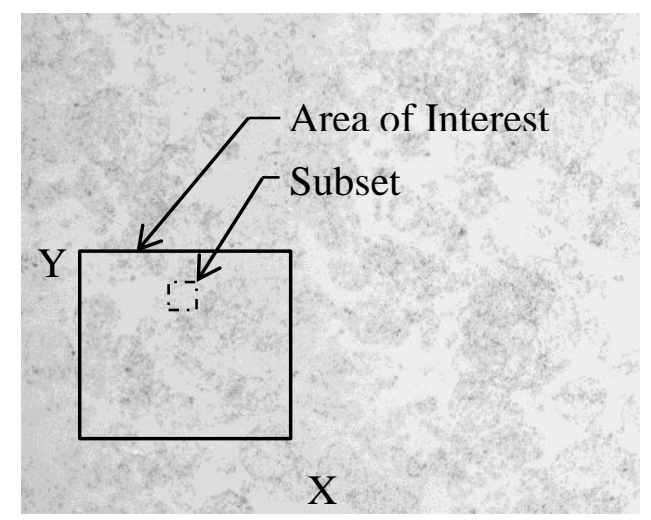

Figure 7. Typical undeformed image.

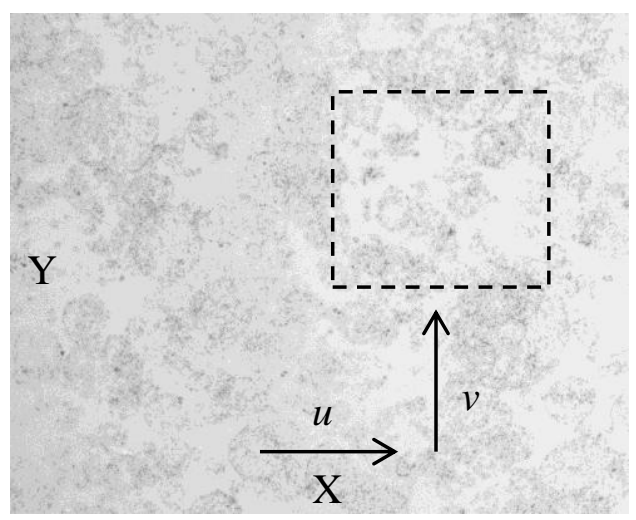

Figure 8. Typical deformed image.

The coarse displacement algorithm calculates the displacements and the correlation coefficient for each subset. The coarse displacement results are then used by the Newton Raphson routine to further refine the displacement results.

The first step in the coarse displacement routine is the conversion of the deformed and undeformed images into their respective ascii gray scale intensity arrays. Once the gray scale intensities of both images are known, the coarse displacement routine breaks the image area of interest into its individual rows and columns to calculate the subset intensities of the undeformed image. The coarse displacement routine does this by taking each row and column in the area of interest of the undeformed image and solves for the subset intensity one half of a subset size on both sides of each row and column. The undeformed image subset intensity is calculated using: 


$$
U I=\sum_{1}^{\text {Subset }} \sum_{1}^{\text {Subset }}(u r i, u c i)^{2}
$$

where uri and uci are the undeformed row and column intensities. The algorithm then calculates the deformed image subset intensity and compares that to the undeformed image subset intensity.

To perform this comparison, the algorithm first calculates the new area of interest based on the estimated displacement parameters. For this procedure, the same area of interest on the deformed image is broken down into the individual rows and columns as before, except the bounds of the estimated row and column displacements are factored in and calculated for one half of a subset on both sides of the displacement corrected row and column. The difference between the undeformed and deformed subset intensities are then calculated using:

$$
\Delta I=\sum_{1}^{\text {Subset }} \sum_{1}^{\text {Subset }}([u r i, u c i]-[d r i, d c i])^{2}
$$

where $d r i$ and $d c i$ are the deformed row and column intensities.

Each time the algorithm calculates the undeformed subset intensity and the change in intensities between the deformed and undeformed image, it calculates the correlation coefficient using:

$$
C C=\frac{\Delta I}{U I}
$$

After the correlation coefficient is calculated, it is then checked against the lowest previous correlation coefficient. For the initial subset, the correlation coefficient is checked against a baseline value of 0.989. Once the algorithm runs through the entire 
area of interest, it stores the row, column combination that yielded the lowest correlation coefficient and saves the calculated $u$ and $v$ displacement values as the optimized values.

Once the optimized values are stored, the algorithm then refines the calculated displacement values over an interval of +1 to -1 pixels. This is achieved by taking the interval and breaking it down over a user-specified number of iterative pixels. Bilinear interpolation is then used to calculate the subpixel intensities through a method similar to the coarse displacement routine. From bilinear interpolation, the difference between the undeformed subset intensity and the subpixel subset intensity is calculated using:

$$
\Delta I s=\sum_{1}^{\text {Subset }} \sum_{1}^{\text {Subset }}([u r i, u c i]-[s r i, s c i])^{2}
$$

where sri and sci are the row and column subpixel intensities. The correlation coefficient is then recalculated, substituting in the subpixel intensity difference in the form:

$$
C C s=\frac{\Delta I s}{U I}
$$

After the correlation coefficient is recalculated, it is initially checked against the previous low from the coarse displacement routine, and then each subsequent interval. If the correlation coefficient is lower than the previous, the displacement values from the coarse displacement routine are added to the corresponding row, column interval displacement and stored as the subpixel optimized $u$ and $v$ displacement values. Once the coarse displacement routine has completed, the user has the option to also smooth the results a desired number of times and over a specified window.

Finally, the algorithm further refines the subpixel coarse displacement result through a Newton Raphson routine. Through bicubic spline interpolation, the subpixel intensity is recalculated. The intensity difference between the undeformed image and the 
subpixel intensity is calculated using the same methodology of Equation IC5, with the subpixel intensity being solved through bicubic spline interpolation as opposed to bilinear interpolation. The correlation coefficient at each location is then checked versus the previously stored correlation coefficient with the optimum value and the associated $u$ and $v$ displacement components being stored. Similarly to the coarse displacement routine, the Newton Raphson routine has the option to smooth the results a desired number of times and over a specified window.

\section{THESIS OVERVIEW}

The goal of this analysis was to use DIC to measure the thermally developed strains in well and poorly adhered PZT films. Subsequent goals of the analysis was to characterize the failure criteria for the PZT film, ODS monolayer system as well as show that DIC is an effective strain measurement technique for a transient, drying sol gel film. Ultimately, this analysis will provide useful insights for predicting and controlling the cracking behavior of any type of solvent-filled thin film system. 


\section{EXPERIMENTAL PROCEDURE}

The necessary materials, equipment, and the processes involved with creation of the PZT thin films and the associated methods for testing and measuring the PZT thin film system are discussed in detail in Section A and Section C. The methods required for

running the DIC code as well as the preparation of results from the output of the DIC procedure are discussed in Section B and Section D. The methods for the data processing associated with the DIC method are discussed in Section E.

\section{A. SAMPLE FABRICATION}

To conduct the tests required by this thesis, several stock materials were necessary. These materials included substrates, PZT sol gel, and a self-assembled monolayer (SAM) solution. A description of each component and the required steps are discussed further in the following sections.

\section{i. SUBSTRATES}

$\mathrm{SiO}_{2}$ coated silicon wafers were chosen as the sample substrates for this thesis due to their desired adhesive characteristics with both PZT and the SAM. Bare silicon wafers were oxidized with a $\mathrm{SiO}_{2}$ layer with a thickness of approximately 100nm. Two types of substrates were used for this work: bare $\mathrm{SiO}_{2}$ coated wafers, which result in good PZT film adhesion and SAM functionalized substrates, which result in poor film adhesion.

\section{ii. PZT SOL GEL}

The PZT stock sol gel prepared follows a variation of the recipe presented by Yi and Sayer (1996). The first step was to dissolve the lead acetate into the acetic acid at a raised temperature of $105^{\circ} \mathrm{C}$ to remove any water present. Yi and Sayer (1996) advise 
lowering the temperature prior to the addition of titanium isopropoxide and zirconium propoxide. However, more desirable results were obtained if the lead acetate and acetic acid components remained at an elevated temperature of $80^{\circ} \mathrm{C}$ for the addition of the titanium isoproxide and zirconium propoxide. Stirring is required during the addition of the titanium isoproxide and zirconium propoxide to initiate the evolution of heat. Distilled water was then added to the solution to help initiate stability and limit the formation of any precipitates.

In accordance to Yi and Sayer (1996), lactic acid was added to create a solution with constant viscosity and to improve the mechanical properties of the sol gel. To limit the possibility of cracking during drying when applied to a substrate, both ethylene glycol and glycerol were added to the stock solution. Table 1 lists the required chemicals for the stock solution utilized for this thesis and Figure 9 presents a flow chart for creating the utilized sol gel solution. The stock solution was then thinned using a 2:1 combination of isopropanol and water.

\begin{tabular}{|c|c|c|}
\hline Chemical & Molecular Formula & Quantity (Grams) \\
\hline Lead Acetate & $\mathrm{Pb}\left(\mathrm{OOCCH}_{3}\right)_{2} * 3 \mathrm{H}_{2} \mathrm{O}$ & 5.000 \\
\hline Acetic Acid & $\mathrm{CH}_{3} \mathrm{COOH}$ & 4.000 \\
\hline Zirconium Propoxide & $\mathrm{Zr}\left(\mathrm{OC}_{3} \mathrm{H}_{7}\right)_{4}$ & 3.848 \\
\hline Titanium Isopropoxide & $\mathrm{Ti}\left[\mathrm{OCH}\left(\mathrm{CH}_{3}\right)_{2}\right]_{4}$ & 2.032 \\
\hline Distilled Water & $\mathrm{H}_{2} \mathrm{O}$ & 4.000 \\
\hline Lactic Acid & $\mathrm{CH}_{3} \mathrm{CHOHCOOH}$ & 1.000 \\
\hline Glycerol & $\mathrm{HOCH}_{2} \mathrm{CHOHCH}_{2} \mathrm{OH}$ & 1.500 \\
\hline Ethylene Glycol & $\mathrm{HOCH}_{2} \mathrm{CH}_{2} \mathrm{OH}$ & 1.000 \\
\hline
\end{tabular}

Table 1. Required chemicals for PZT sol gel stock solution. 


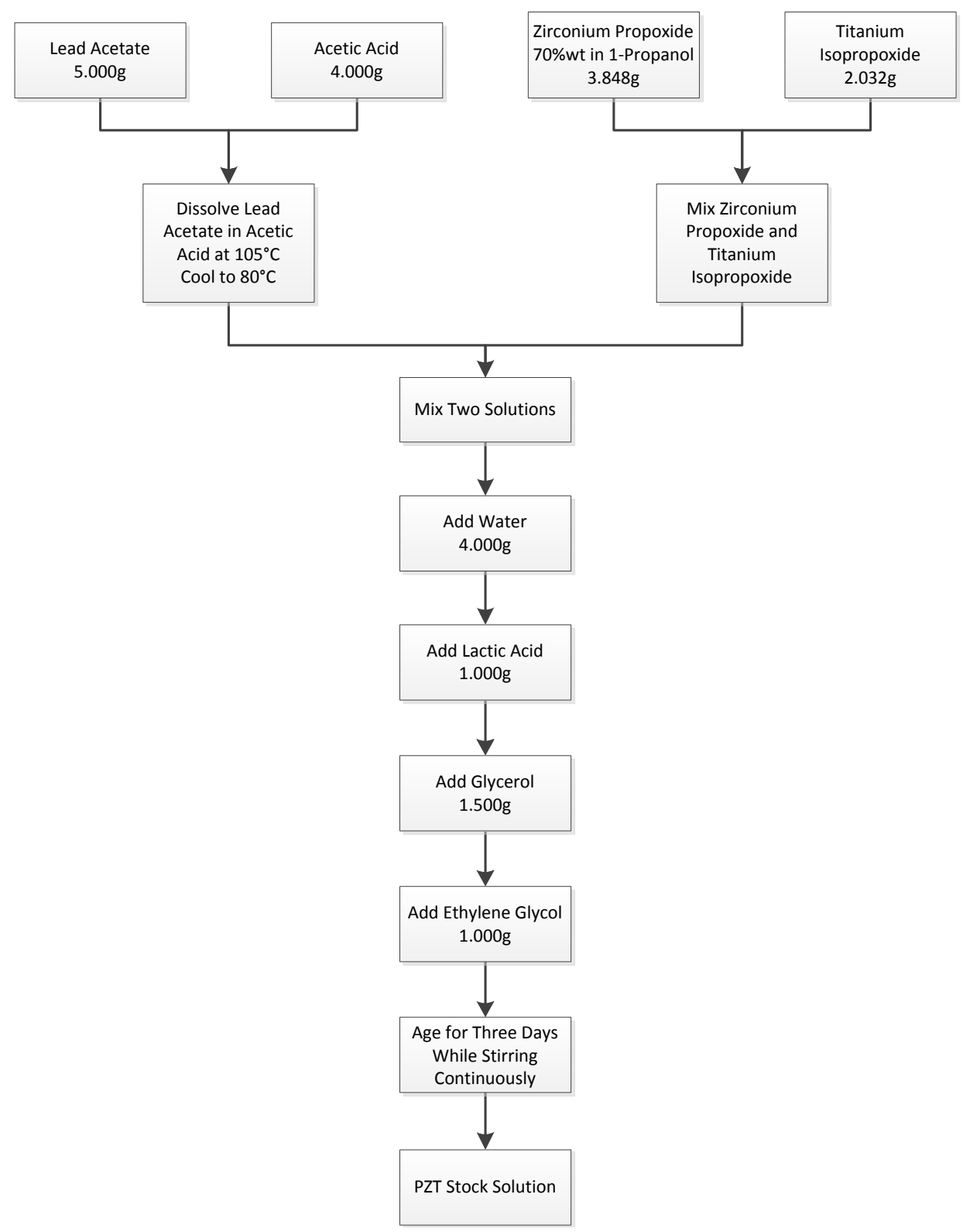

Figure 9. Flow chart for preparation of PZT stock solution.

\section{iii. SELF ASSEMBLED MONOLAYER}

Octadecyltrichlorosilane, or ODS, is a self-assembled monolayer with a hydrophobic head group. When combined with hexanes, ODS produces a solution that is easily spun onto a substrate. When deposited onto $\mathrm{SiO}_{2}$, the ODS solution promotes poor adhesion between the PZT sol gel solution and the bare substrate, which allows for 
cracking of the PZT to occur easily and at lower temperatures. The ODS solution utilized is shown in Table 2 and a flow chart for the creating of the ODS solution is shown in Figure 10.

\begin{tabular}{|c|c|c|}
\hline Chemical & Molecular Formula & Quantity (mL) \\
\hline Octadecylrichlorosilane & $\mathrm{C}_{18} \mathrm{H}_{37} \mathrm{Cl}_{3} \mathrm{Si}$ & 0.10 \\
\hline Hexane & $\mathrm{C}_{6} \mathrm{H}_{14}$ & 10.00 \\
\hline
\end{tabular}

Table 2. Required chemicals for ODS solution.

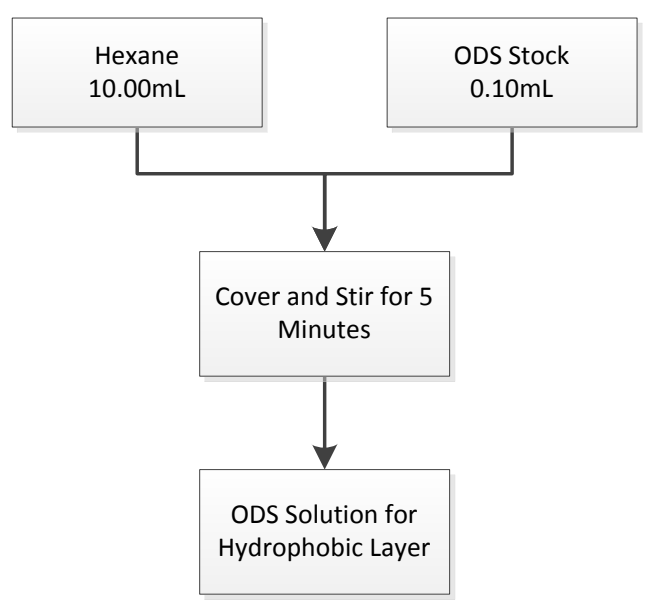

Figure 10. Flow chart for preparation of ODS solution.

\section{iv. SUBSTRATE PREPARATION}

Full size, 4" diameter oxidized silicon substrates were scribed to a test sample size of approximately $0.75 " \times 0.75$ " in length and width. Prior to any deposition of ODS or PZT, each $\mathrm{SiO}_{2}$ substrate went through a three-stage rinsing process of acetone, distilled water, and isopropanol. The substrate was thoroughly dried using compressed air between each rinse. The drying and rinsing process was followed by 10 minutes of exposure in an UV environment. 


\section{v. ODS DEPOSITION}

The hydrophobic ODS layer consisted of $0.5 \mathrm{~mL}$ of ODS flood deposited on the clean substrate through a filter syringe and spun using a Laurell WS-400BZ-6NPP-Lite spinner at a rate of 3000 RPM's for 30 seconds. The Laurall spinner used for all sample preparation is shown Figure 11.

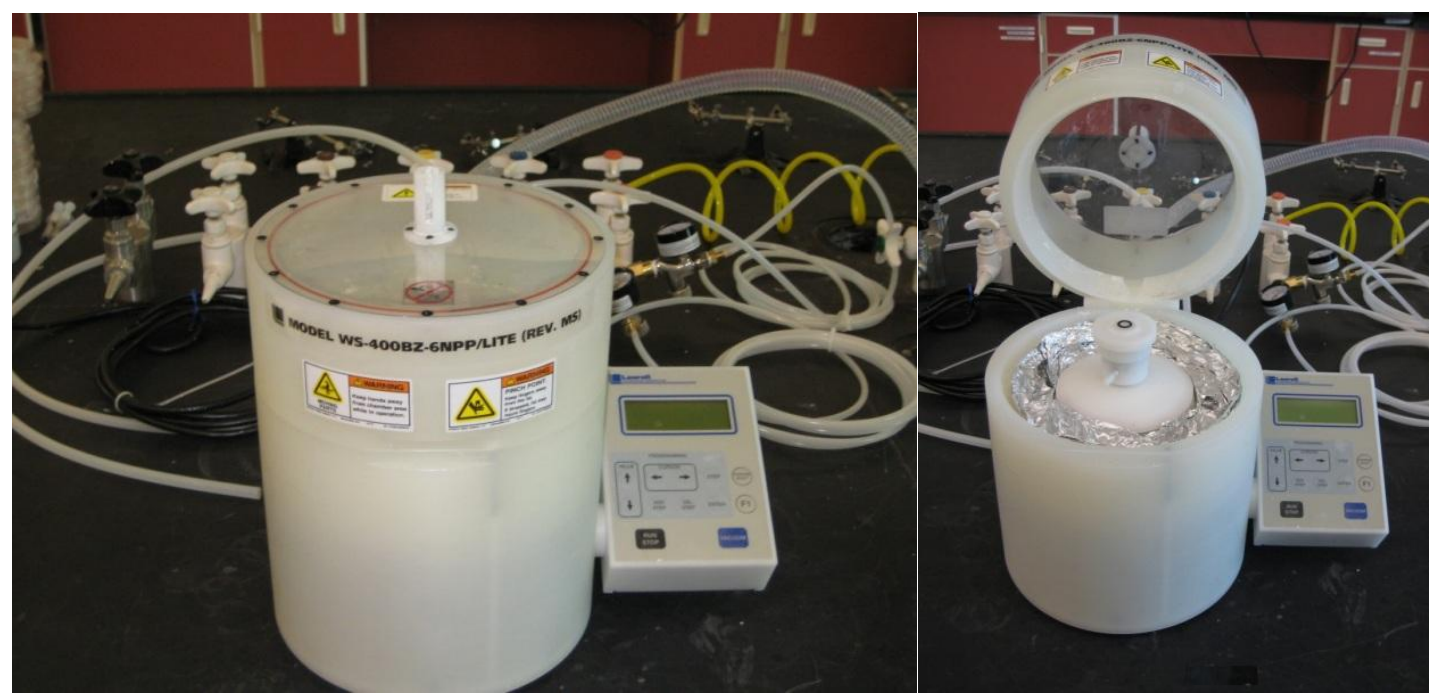

Figure 11. Laurell spinner.

Immediately following the ODS deposition, $0.5 \mathrm{~mL}$ of hexane was deposited through spin disposition utilizing the same ODS spinning program. Refer to Table 9 in the following sections for measured film thicknesses.

\section{vi. PZT DEPOSITON}

PZT deposition was achieved through the use of the Laurell spinner and filtered syringes. Each layer of PZT sol gel consisted of flood depositing 0.3mL of PZT sol gel and then spinning the solution for 60 seconds at a rate of 3000 RPM's. Refer to Table 9 in the following sections for measured film thicknesses. 


\section{vii. SPECKLE PATTERNING}

The required speckle pattern necessary for the DIC procedure was achieved through airbrushing nanoparticles onto the surface of the cured samples. Nanoparticles were chosen as the speckling medium of choice over the traditional ink speckle since the nanoparticles were too small to influence crack growth during thermal loading. Due to the presence of solvents, the samples required an hour drying time prior to any speckling. Figure 12 shows an SEM image of nanoparticles along a crack channel.

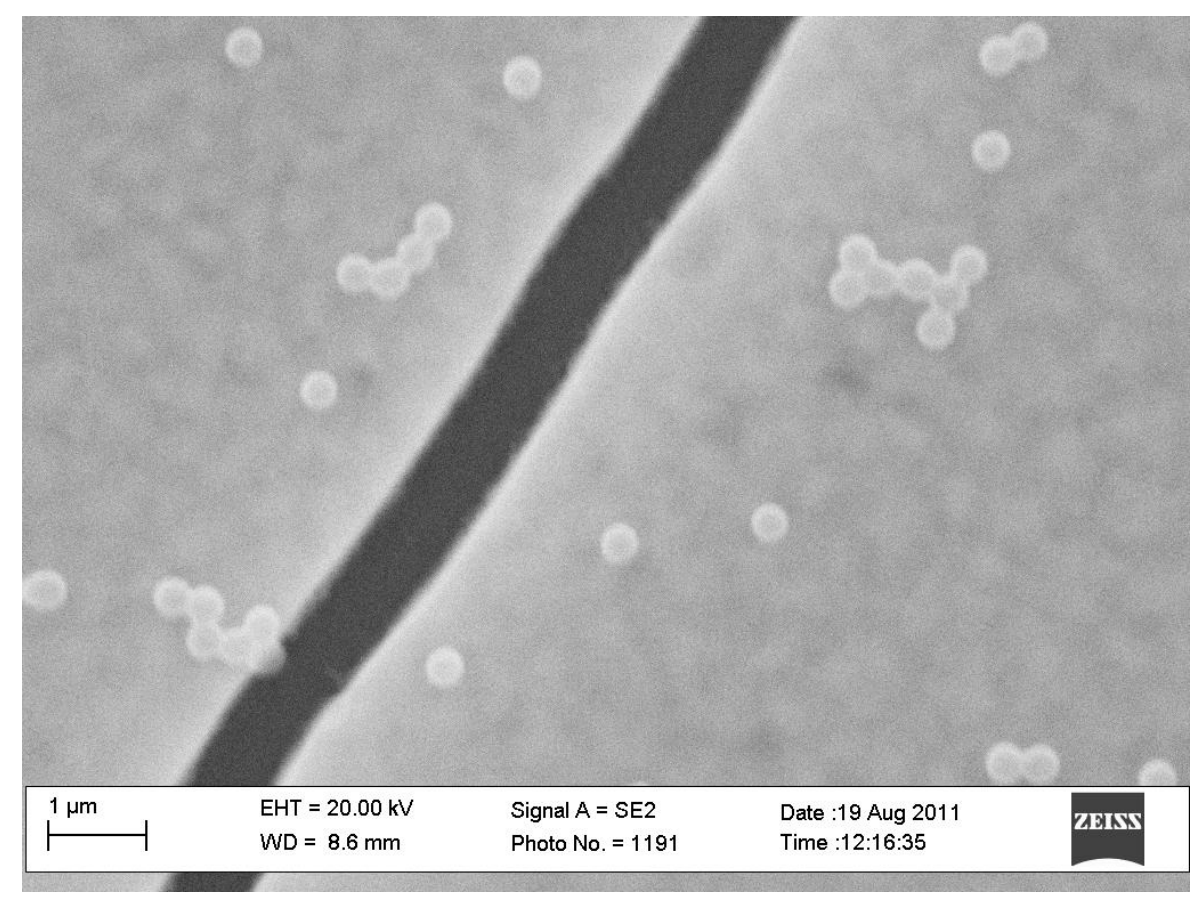

Figure 12. SEM image of nanoparticles along crack channel.

The speckling media used were silica nanoparticles (200nm dia.) suspended in ethanol. The nanoparticles in ethanol were sonicated for a minimum of 30 minutes prior to airbrushing. The airbrush allowed for the silica nanoparticle to be dispersed onto the sample surface and the ethanol to atomize, minimizing any imperfections due to the 
added solvent. Figure 13 shows the typical speckle pattern provided by the airbrushed nanoparticle technique.

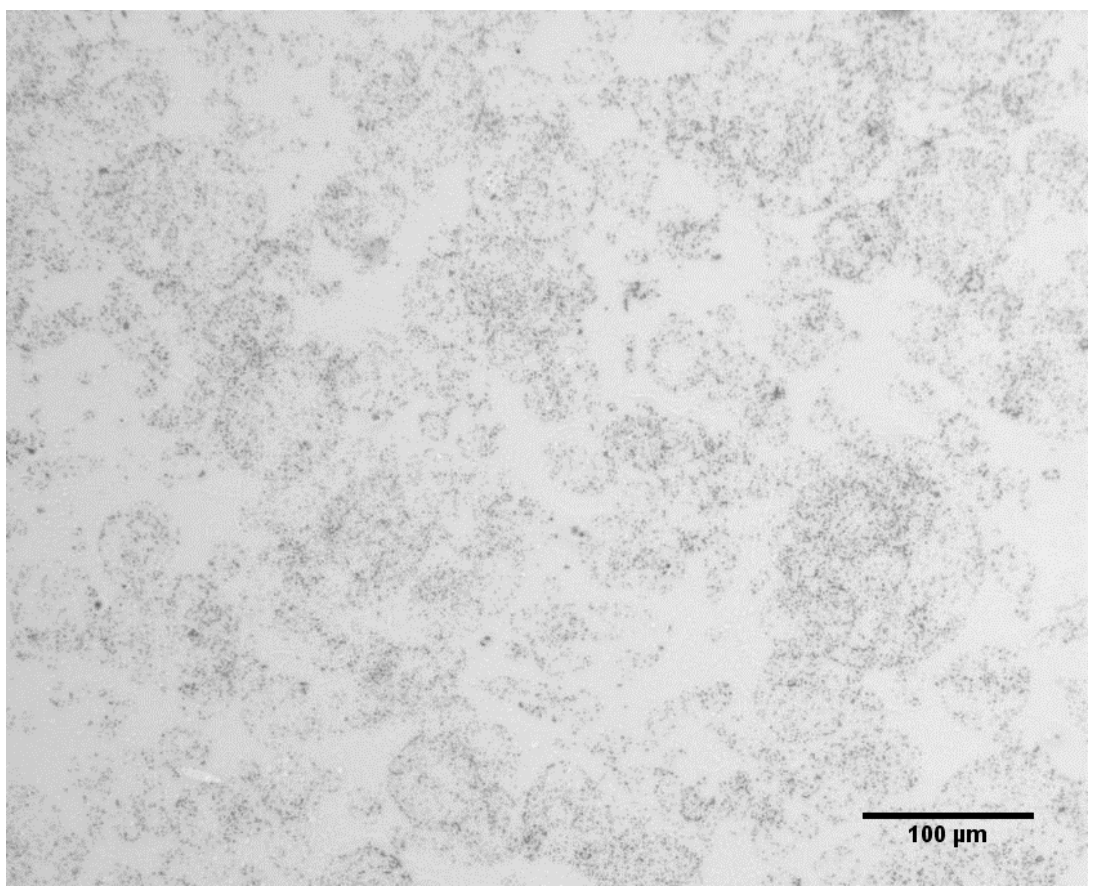

Figure 13. Typical speckle pattern.

\section{B. BASELINE DIGITAL IMAGE CORRELATION TESTS}

\section{i. RIGID BODY MOTION TESTING}

The DIC procedure was verified with a series of rigid body motion (RBM) tests. The tests were conducted using a linear translational stage coupled with an optical linear encoder feedback to ensure accurate linear displacements. The tests were conducted on a bare silicon wafer backside. The silicon wafer backside was chosen due to the inherent crystalline structure of the silicon, which provided a suitable speckle pattern for correlation.

DIC was performed at various applied displacements and the results were compared with the optical encoders feedback for both the coarse displacement routine and the Newton Raphson routine results. Neither the coarse displacement routine nor the 
Newton Raphson routine results were smoothed. Table 3 and Table 4 show the RBM comparisons for the coarse displacement and Newton Raphson routines.

\begin{tabular}{|c|c|c|c|c|c|}
\hline \multicolumn{6}{|l|}{ Coarse Displacement Results } \\
\hline Applied $(\mu \mathrm{m})$ & DIC $(\mu \mathrm{m})$ & $\%$ of App. & \% Diff. & Dist. Diff. & Pixel Res. \\
\hline 0.5 & 0.4480 & 0.8961 & 0.1039 & 0.0520 & 0.0695 \\
\hline 1 & 0.9613 & 0.9613 & 0.0387 & 0.0387 & 0.0518 \\
\hline 2.5 & 2.4792 & 0.9917 & 0.0083 & 0.0208 & 0.0278 \\
\hline 5 & 4.8649 & 0.9730 & 0.0270 & 0.1351 & 0.1807 \\
\hline 7.5 & 7.5158 & 0.9979 & 0.0021 & 0.0158 & 0.0212 \\
\hline 10 & 9.9439 & 0.9944 & 0.0056 & 0.0561 & 0.0750 \\
\hline 20 & 19.8473 & 0.9924 & 0.0076 & 0.1527 & 0.2042 \\
\hline 30 & 29.8250 & 0.9942 & 0.0058 & 0.1750 & 0.2340 \\
\hline 40 & 40.0449 & 0.9989 & 0.0011 & 0.0449 & 0.0600 \\
\hline 50 & 50.3254 & 0.9935 & 0.0065 & 0.3254 & 0.4351 \\
\hline \multicolumn{7}{|l}{} & & Avg: & 0.1359 \\
\hline
\end{tabular}

Table 3. Coarse displacement routine RBM results.

\begin{tabular}{|c|c|c|c|c|c|}
\hline \multicolumn{6}{|l|}{ Newton Raphson Results } \\
\hline Applied $(\mu \mathrm{m})$ & DIC $(\mu \mathrm{m})$ & \% of App. & \% Diff. & Dist. Diff. & Pixel Res. \\
\hline 0.5 & 0.4427 & 0.8855 & 0.1145 & 0.0573 & 0.0766 \\
\hline 1 & 0.9445 & 0.9445 & 0.0555 & 0.0555 & 0.0742 \\
\hline 2.5 & 2.4865 & 0.9946 & 0.0054 & 0.0135 & 0.0180 \\
\hline 5 & 4.8674 & 0.9735 & 0.0265 & 0.1326 & 0.1772 \\
\hline 7.5 & 7.5073 & 0.9990 & 0.0010 & 0.0073 & 0.0097 \\
\hline 10 & 9.9425 & 0.9943 & 0.0057 & 0.0575 & 0.0769 \\
\hline 20 & 19.8471 & 0.9924 & 0.0076 & 0.1529 & 0.2044 \\
\hline 30 & 29.8322 & 0.9944 & 0.0056 & 0.1678 & 0.2244 \\
\hline 40 & 40.0459 & 0.9989 & 0.0011 & 0.0459 & 0.0614 \\
\hline 50 & 50.3188 & 0.9937 & 0.0063 & 0.3188 & 0.4263 \\
\hline \multicolumn{7}{|l}{} & & Avg: & 0.1349 \\
\hline
\end{tabular}

Table 4. Newton Raphson routine RBM results.

Figure 14 and Figure 15 show the coarse displacement and Newton Raphson results plotted over a range of zero to 50 microns. Figure 16 and Figure 17 show the 
coarse displacement and Newton Raphson results plotted over a range of zero to 10 microns.

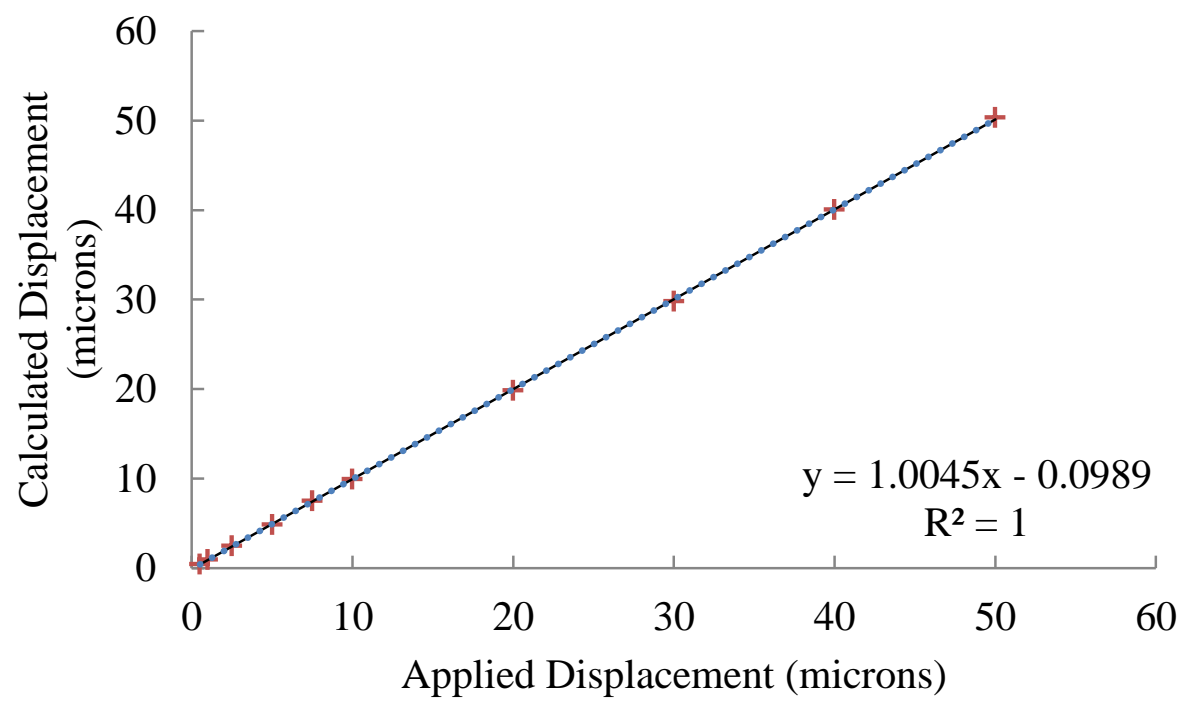

Figure 14. Coarse displacement routine over entire range.

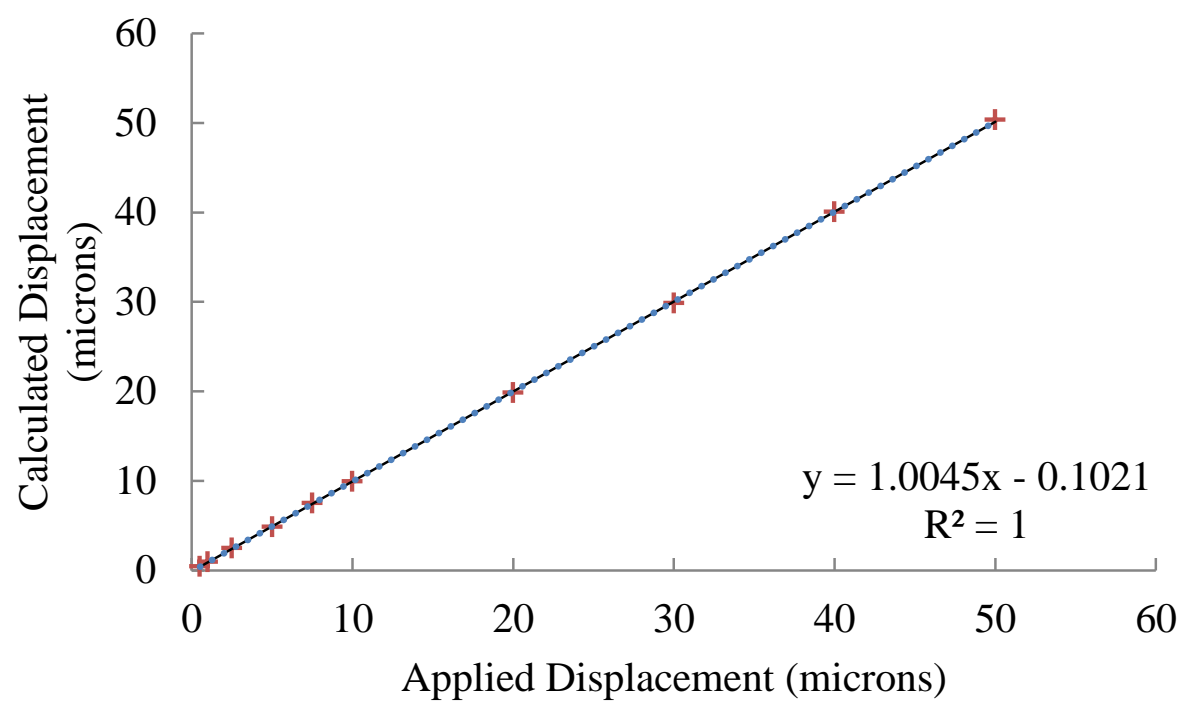

Figure 15. Newton Raphson routine over entire range. 


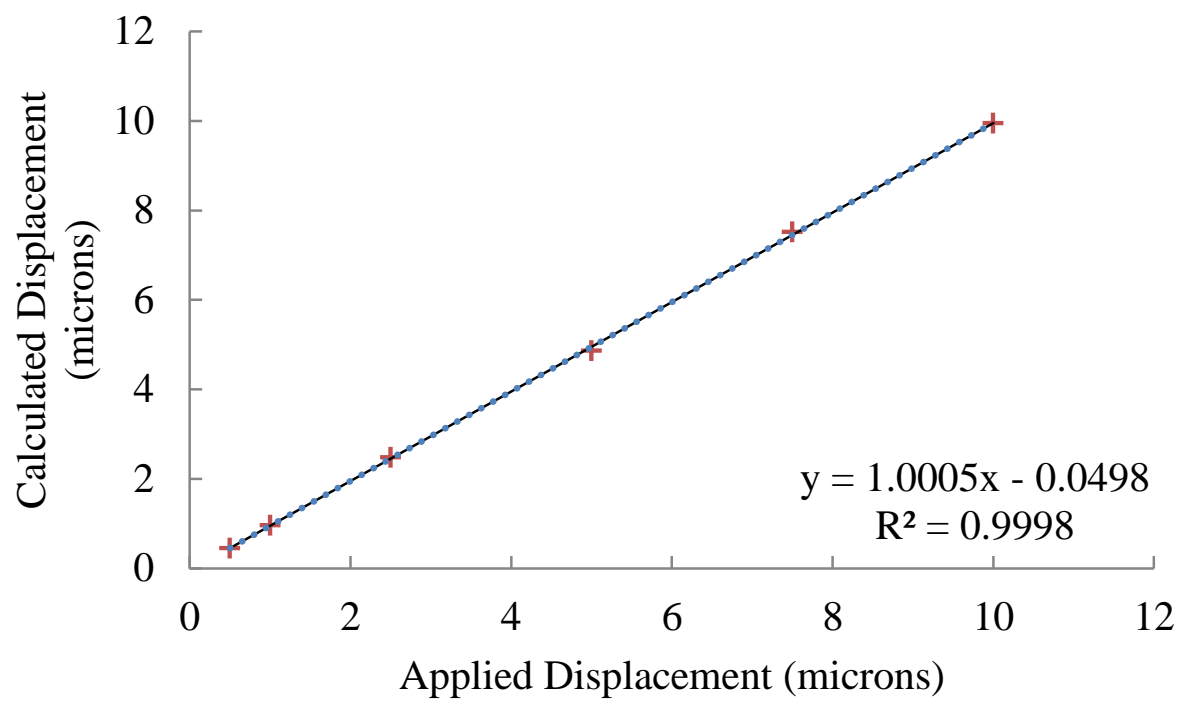

Figure 16. Coarse displacement routine over reduced range.

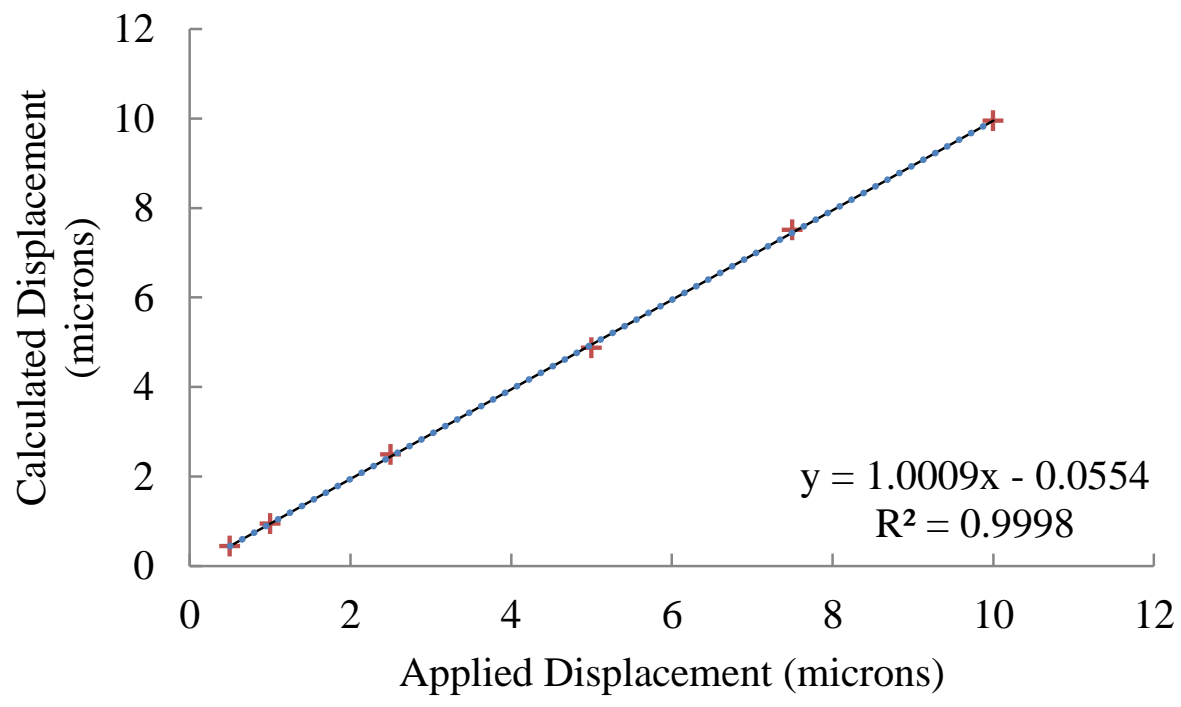

Figure 17. Newton Raphson routine over reduced range.

As indicated by the tables and figures, the DIC method provides allowable confidence across the range of displacements and yields approximately a (1/7) pixel resolution across the range. 


\section{ii. SUBSET SIZE, ITERATIVE PIXEL, AND CORRELATION COEFFICIENT COMPARISONS BASED ON RBM TESTING}

Similarly to the utilized speckle pattern, the user-input parameters of subset size and the iterative pixels have a significant effect on the obtained results. In an attempt to minimize this effect, a comparison of the RBM results for 0.5 microns and 2.5 microns was conducted for various subset sizes and iterative pixels to approximate the optimum combination. The 0.5 micron and 2.5 micron RBM test result were used because the crack channels presented in this thesis were nearest to that range. This comparison was performed for the coarse displacement and the Newton Raphson result. The results are shown in Table 5 and Table 6 with the subset and iterative pixel combination of choice appearing in green.

\begin{tabular}{|c|c|c|c|c|c|c|}
\hline \multicolumn{7}{|c|}{ Coarse Displacement Results } \\
\hline $\begin{array}{l}\text { Acuator } \\
\text { Displ. } \\
\text { (microns) }\end{array}$ & $\begin{array}{l}\text { Subset Size } \\
\text { (pixels) }\end{array}$ & $\begin{array}{c}\text { Iterative } \\
\text { Pixels }\end{array}$ & $\begin{array}{l}\text { Avg. Corr. } \\
\text { Coeff. }\end{array}$ & $\begin{array}{c}\text { Corr. Coeff. } \\
\text { Std. }\end{array}$ & $\begin{array}{l}\text { Avg. DIC } \\
\text { Displ. } \\
\text { (microns) }\end{array}$ & $\begin{array}{c}\text { DIC Displ. } \\
\text { Std. } \\
\text { (microns) }\end{array}$ \\
\hline 0.5 & 13 & 10 & 0.000139 & 0.000050 & 0.448028 & 0.009969 \\
\hline 0.5 & 21 & 10 & 0.000132 & 0.000035 & 0.448740 & 0.002581 \\
\hline 0.5 & 31 & 10 & 0.000128 & 0.000023 & 0.448740 & 0.000000 \\
\hline 0.5 & 13 & 20 & 0.000141 & 0.000054 & 0.447722 & 0.010033 \\
\hline 0.5 & 21 & 20 & 0.000132 & 0.000034 & 0.448740 & 0.000000 \\
\hline 0.5 & 31 & 20 & 0.000128 & 0.000023 & 0.448740 & 0.000000 \\
\hline 2.5 & 13 & 10 & 0.000180 & 0.000057 & 2.479237 & 0.028003 \\
\hline 2.5 & 21 & 10 & 0.000178 & 0.000041 & 2.473720 & 0.019771 \\
\hline 2.5 & 31 & 10 & 0.000176 & 0.000027 & 2.469939 & 0.011677 \\
\hline 2.5 & 13 & 20 & 0.000182 & 0.000058 & 2.479941 & 0.027822 \\
\hline 2.5 & 21 & 20 & 0.000179 & 0.000041 & 2.474175 & 0.020501 \\
\hline 2.5 & 31 & 20 & 0.000176 & 0.000027 & 2.469936 & 0.011677 \\
\hline
\end{tabular}

Table 5. Coarse displacement routine subset and iterative pixel comparison. 


\begin{tabular}{|c|c|c|c|c|c|c|}
\hline \multicolumn{2}{|c|}{ Newton Raphson Results } & \multicolumn{1}{|c|}{} & Avg. DIC \\
$\begin{array}{c}\text { Acuator } \\
\text { Displ. } \\
\text { (microns) }\end{array}$ & $\begin{array}{c}\text { Subset Size } \\
\text { (pixels) }\end{array}$ & $\begin{array}{c}\text { Iterative } \\
\text { Pixels }\end{array}$ & $\begin{array}{c}\text { Avg. Corr. } \\
\text { Coeff. }\end{array}$ & $\begin{array}{c}\text { Corr. Coeff. } \\
\text { Std. }\end{array}$ & $\begin{array}{c}\text { Displ. Displ. } \\
\text { (microns) }\end{array}$ & $\begin{array}{c}\text { Std. } \\
\text { (microns) }\end{array}$ \\
\hline 0.5 & 13 & 10 & 0.000172 & 0.000064 & 0.442746 & 0.016691 \\
\hline 0.5 & 21 & 10 & 0.000167 & 0.000044 & 0.444448 & 0.008250 \\
\hline 0.5 & 31 & 10 & 0.000166 & 0.000031 & 0.445122 & 0.005377 \\
\hline 0.5 & 13 & 20 & 0.000175 & 0.000069 & 0.442281 & 0.016840 \\
\hline 0.5 & 21 & 20 & 0.000167 & 0.000043 & 0.444216 & 0.008003 \\
\hline 0.5 & 31 & 20 & 0.000165 & 0.000030 & 0.445435 & 0.005392 \\
\hline 2.5 & 13 & 10 & 0.000207 & 0.000072 & 2.486516 & 0.023339 \\
\hline 2.5 & 21 & 10 & 0.000206 & 0.000049 & 2.484581 & 0.013541 \\
\hline 2.5 & 31 & 10 & 0.000206 & 0.000033 & 2.483624 & 0.009104 \\
\hline 2.5 & 13 & 20 & 0.000210 & 0.000071 & 2.487063 & 0.022553 \\
\hline 2.5 & 21 & 20 & 0.000205 & 0.000047 & 2.484145 & 0.013213 \\
\hline 2.5 & 31 & 20 & 0.000205 & 0.000033 & 2.483602 & 0.009202 \\
\hline
\end{tabular}

Table 6. Newton Raphson routine subset and iterative pixel comparison.

\section{iii. CORRELATION COEFFICIENT OF UTILIZED SPECKLE PATTERN}

The percent by mass of nanoparticles to ethanol was chosen based on which concentration provided the optimum correlation compared with the wafer backside used for the RBM comparisons. Table 7 shows the correlation coefficient comparison between various nanoparticle concentrations and the backside of the wafer for both the coarse displacement routine and the Newton Raphson routine. The concentration of choice is shown in green. 


\begin{tabular}{|l|c|c|c|c|}
\hline Nano Particle Speckle vs. Wafer Backside Comparison \\
\hline & Coarse Displacement & \multicolumn{2}{|c|}{ Newton Raphson } \\
\hline & $\begin{array}{c}\text { Avg. Corr. } \\
\text { Coeff. }\end{array}$ & $\begin{array}{c}\text { Corr. } \\
\text { Coeff. } \\
\text { Std. }\end{array}$ & $\begin{array}{c}\text { Avg. } \\
\text { Corr. } \\
\text { Coeff. }\end{array}$ & $\begin{array}{c}\text { Corr. } \\
\text { Coeff. } \\
\text { Std. }\end{array}$ \\
\hline Solution \& Speckle & 0.001074 & 0.000881 & 0.001375 & 0.001262 \\
\hline 10\% Nano in Ethanol & 0.001023 & 0.001535 & 0.000917 & 0.001601 \\
\hline 5\% Nano in Ethanol & 0.001397 & 0.001676 & 0.002496 & 0.003084 \\
\hline 2.5\% Nano in Ethanol & 0.000128 & 0.000023 & 0.000166 & 0.000031 \\
\hline Wafer Backside from RBM Tests & \multicolumn{5}{|l|}{} \\
\hline * Tests were conducted with 31 subset size and 10 itv pixels \\
\hline
\end{tabular}

Table 7. Correlation coefficient comparison of various nanoparticle concetrations.

Once the concentration of choice was known, the subset size was revisited for a verification of the subset and iterative pixel comparison now based on the utilized speckle. Since the iterative pixels have less of an effect on the correlation coefficient when compared to the subset size, the iterative pixels was set to 10 for all trials. The results of the subset comparison are shown in Table 8 with the chosen subset size shown in green.

\begin{tabular}{|l|c|c|c|c|c|}
\hline \multicolumn{6}{|c|}{ 5\% Nano Particle in Ethanol Speckle Subset Comparison } \\
\hline \multicolumn{2}{|c|}{} & \multicolumn{2}{|c|}{ Coarse Displacement } & Newton Raphson \\
\hline & $\begin{array}{c}\text { Subset } \\
\text { Size } \\
\text { (pixels) }\end{array}$ & $\begin{array}{c}\text { Avg. Corr. } \\
\text { Coeff. }\end{array}$ & $\begin{array}{c}\text { Corr. } \\
\text { Coeff. } \\
\text { Std. }\end{array}$ & $\begin{array}{c}\text { Avg. } \\
\text { Corr. } \\
\text { Coeff. }\end{array}$ & $\begin{array}{c}\text { Corr. } \\
\text { Coeff. } \\
\text { Std. }\end{array}$ \\
\hline PZT & 13 & 0.000837 & 0.001903 & 0.000827 & 0.002393 \\
\hline PZT & 21 & 0.000971 & 0.001779 & 0.000882 & 0.001931 \\
\hline PZT & 31 & 0.001023 & 0.001535 & 0.000917 & 0.001601 \\
\hline
\end{tabular}

Table 8. Utilized speckle pattern subset comparison.

\section{IMAGE CAPTURE}

A Leica optical microscope was coupled with a Retiga CCD monochrome camera to provide the image acquisition capabilities required to apply the DIC analysis for each of the samples. The Retiga-4000R provides $2048 \times 2048$ pixel monochrome images with a 
resolution of $0.7479 \mu \mathrm{m} /$ pixel for the $10 \mathrm{x}$ objective and up to 12 bit digital output. For this thesis, only 8bit digital output was utilized based on the limitation of the photo editing software. The Retiga-4000R provides $4 \mathrm{fps}$ at full $12 \mathrm{bit}$ resolution and a maximum $125 \mathrm{fps}$ refresh rate (with binning and region of interest functions utilized), which aided in the capture of the displacement fields up to the point of film failure.

The Retiga 4000R was used with the imaging software QCapture Pro 6. The QCapture Pro 6 software interface provides a means for capturing multiple images over a specified period of time, the ability to adjust exposure, and live histograms. This is beneficial for evaluating image focus and speckle size prior to image capture.

For final testing, a Labview program was developed, which effectively synchronized with the TMS 94 temperature controller (discussed in the following sections) and the Retiga 4000R. This allowed for sequential image capture across the thermal loading cycle with accurate temperature stamps associated with each image. Final images were $840 \times 680$ pixels, which provided accurate full field images of the area of interest, as well as eliminated the possibility of objective distortion at the edges of the full field 2048x2048 pixel images. 


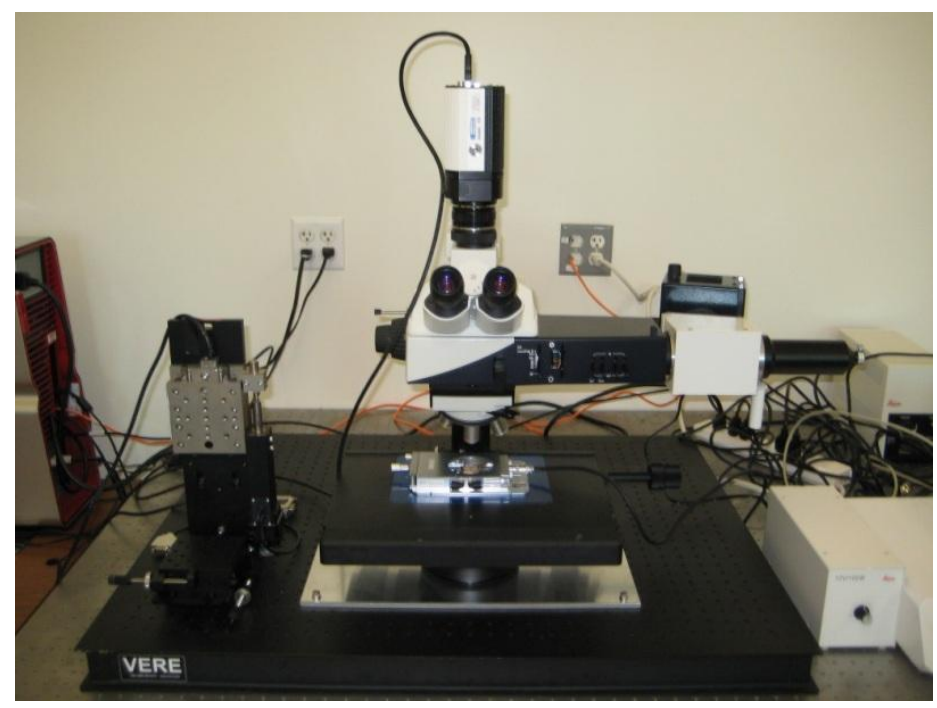

Figure 18. Leica MST49 optical microscope with Retiga-4000R.

\section{THERMAL TESTING}

Thermal loading was achieved through the usage of a LinkAm TMS 94 thermal controller. The TMS 94 allowed for various heating rates to be specified as well as provided a stability of $+/-0.1^{\circ} \mathrm{C}$. The LinkAm hot stage is shown in Figure 19 with the LinkAm TMS 94 controller shown in Figure 20. The TMS 94 was interfaced with the computer and camera software through a LabView VI. 


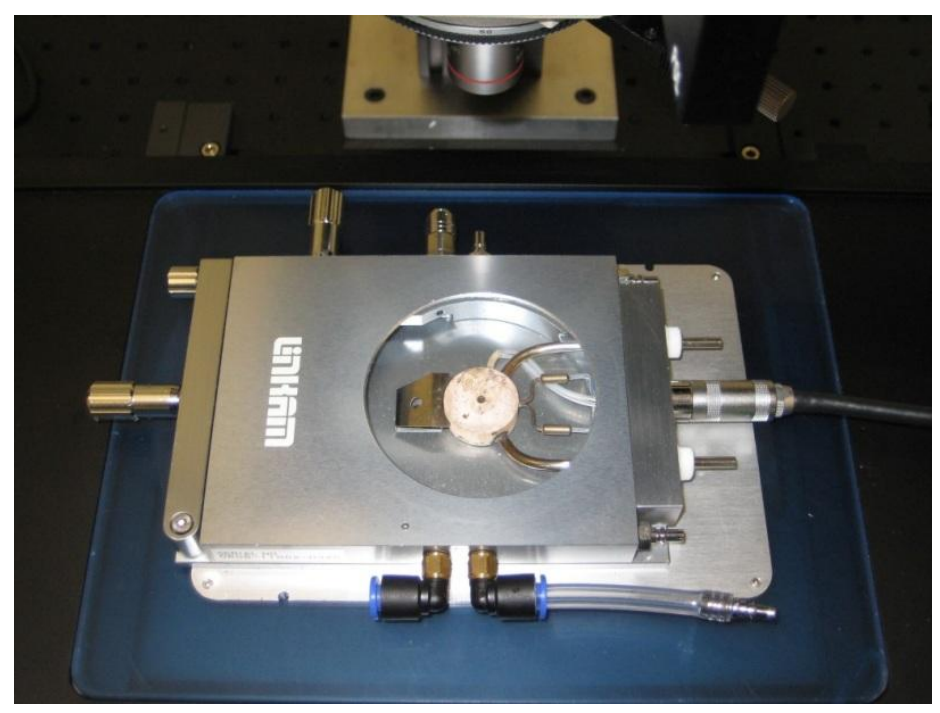

Figure 19. LinkAm hot stage.

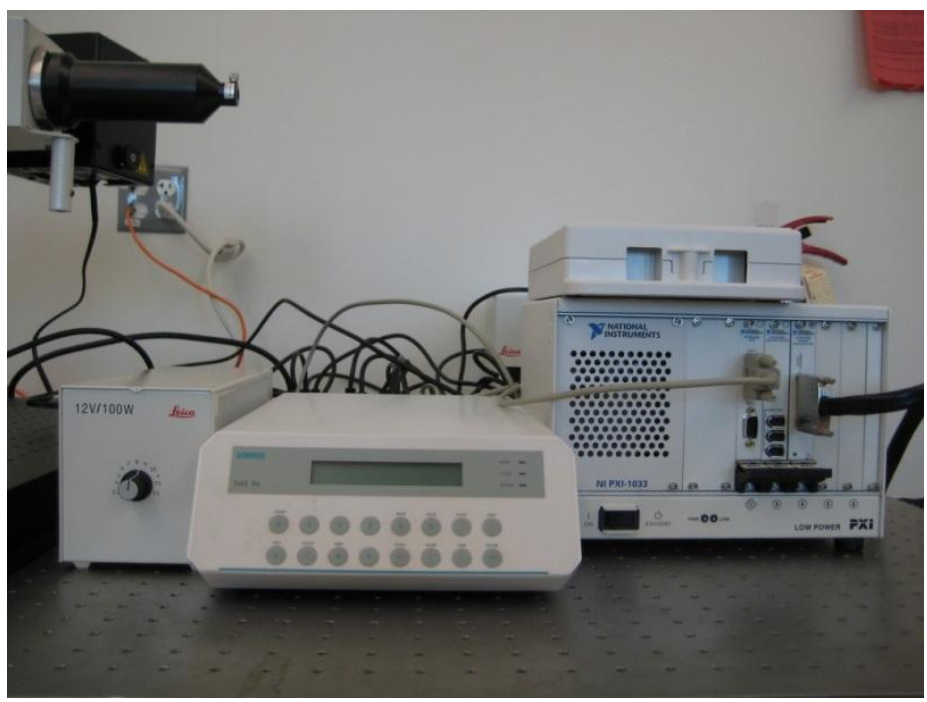

Figure 20. LinkAm TMS 94 controller.

\section{E. DATA PROCESSING}

Due to the fact that DIC is an experimental mechanics technique, a considerable amount of data processing was necessary for each sample. Figure 21 shows the simplified steps of the data processing required for each sample with each step being discussed in detail in the following pages. 


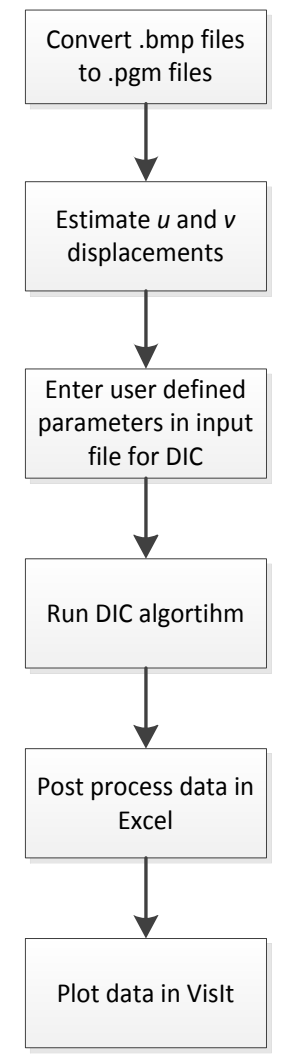

Figure 21. DIC data processing flowchart.

As indicated by Figure 21, the first data processing step is to convert the .bmp bitmap images from the LabView interface into their ascii, grayscale equivalent .pgm files. This process is achieved through the use of the photo processing and manipulation software, GIMP.

The second step is to estimate the $u$ and $v$ displacement ranges for the DIC algorithm. This is achieved through a relatively straight-forward process of selecting several distinguishable points on the undeformed image and recording their respective $x$ and $y$ coordinates. These same points are then located on the deformed image and the respective $x$ and $y$ coordinates are recorded. From the undeformed and deformed coordinates of the selected points, the $u$ and $v$ displacements are calculated with the minimums and maximums being recorded and entered into the DIC input file. 
After the $u$ and $v$ displacement ranges are approximated and entered into the DIC input file, the remaining user-defined parameters are entered. The user then enters the image files for the undeformed and the deformed ascii, grayscale images as well as the image dimensions and the area of interest. The subset size and iterative pixels are then set to the user-specified optimum range based on the utilized speckle pattern and the scaling factor for the utilized microscope objective is entered. A subset size of 31 pixels with 10 pixels per iteration along with an area of interest of 200x200 pixels was utilized for this thesis. Additionally, the Newton Raphson results were smoothed over a window of $3 \times 3,29$ times.

Then the DIC algorithm was run for the specified parameters with both the coarse displacement routine and the Newton Raphson routine being performed. The output of the DIC algorithm were tec files that are directly compatible with the VisIt plotting software and are easily entered into Excel for data post processing.

The primary purpose of the data post processing is to calculate the strains present in each sample. The strains are calculated from the measured displacements through a forward finite difference method coupled with a weighting function. The weighting function is a Gauss-Hermite of the form:

$$
f(x)=e^{-0.1 x^{2}}
$$

where $f(x)$ is evaluated at each subset interval. Figure 22 shows a plot of the weighting function plotted over the subset intervals.

The DIC algorithm has the capability to directly calculate the strains and the strain cross derivatives, but since the point mapping is based on a Taylor series expansion (Dally 2005), the algorithm weights the displacement correlations greater than the 
derivative correlations, yielding greater confidence in the displacement results. The weighting function was used because the algorithm solves for displacement values at the center of each subset. Therefore, the greatest confidence was at the subset center point.

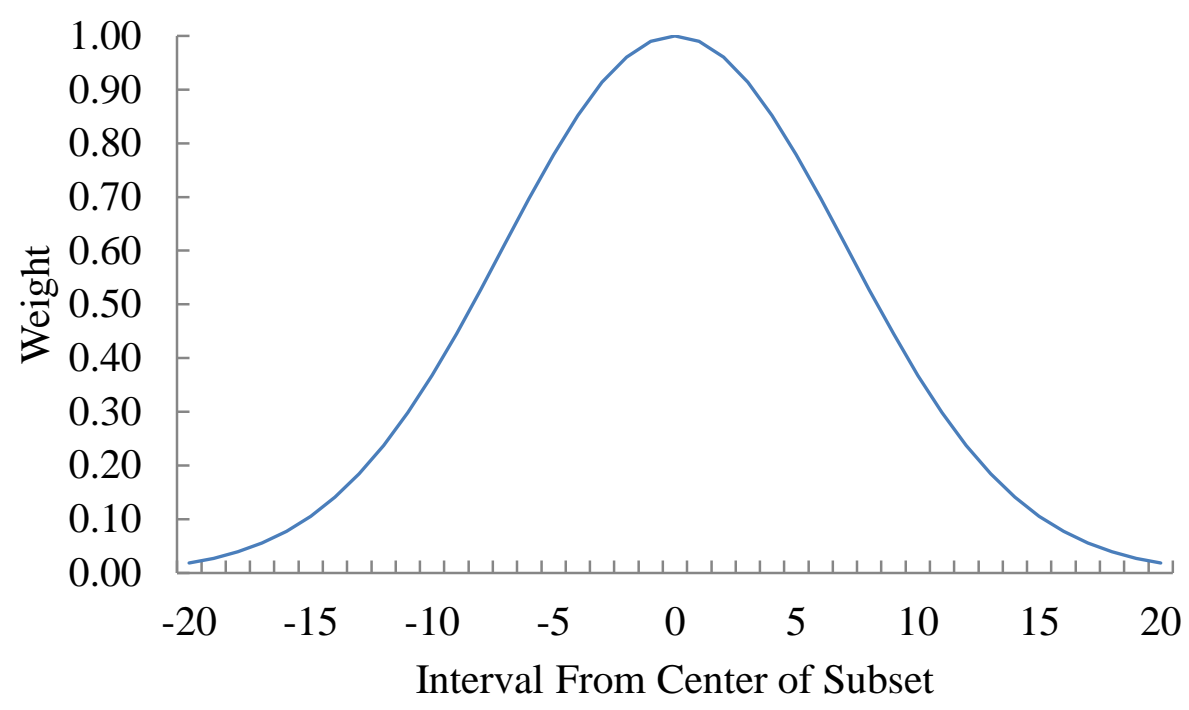

Figure 22. Subset weighting function plotted over the subset intervals.

The final data processing step was to graphically display the results using VisIt. Through the use of VisIt, the data in the tec output files were shown in the form of psuedocolor plots. As an additional baseline test, the thermally developed strains for a bare silicon wafer were calculated and plotted in VisIt to provide an example of the psuedocolor plots presented in the results and discussion section. 


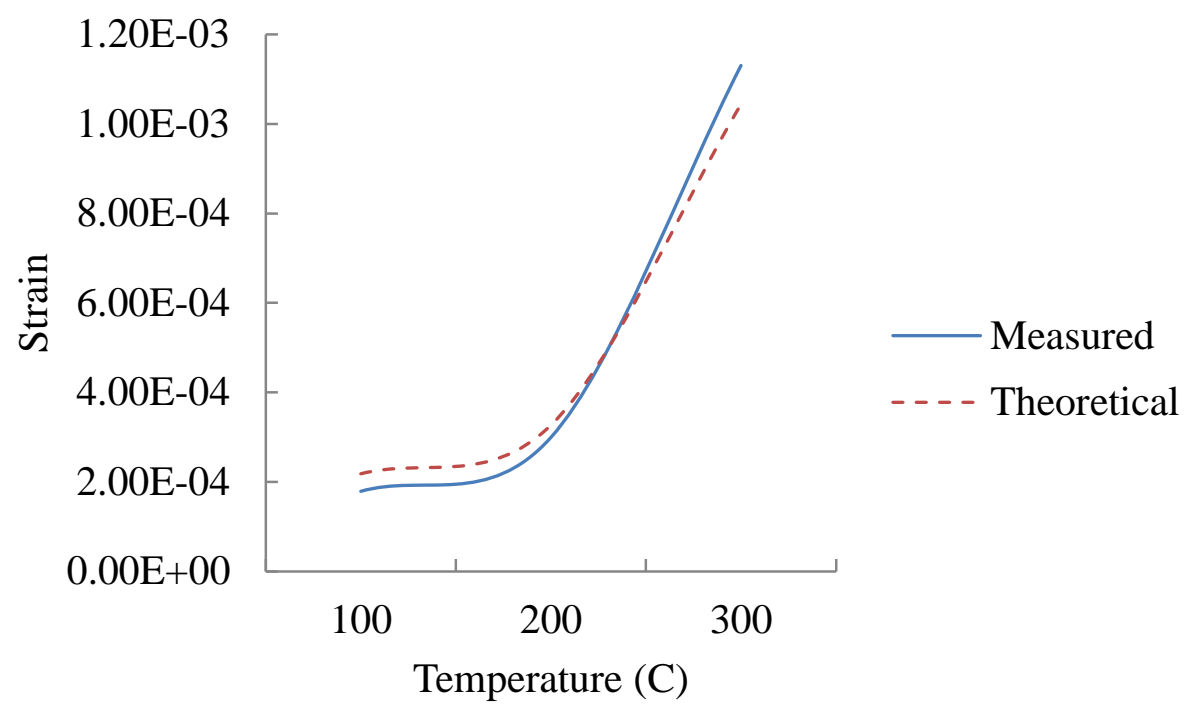

Figure 23. Measured versus theoretical thermally developed strains in a bare silicon wafer.

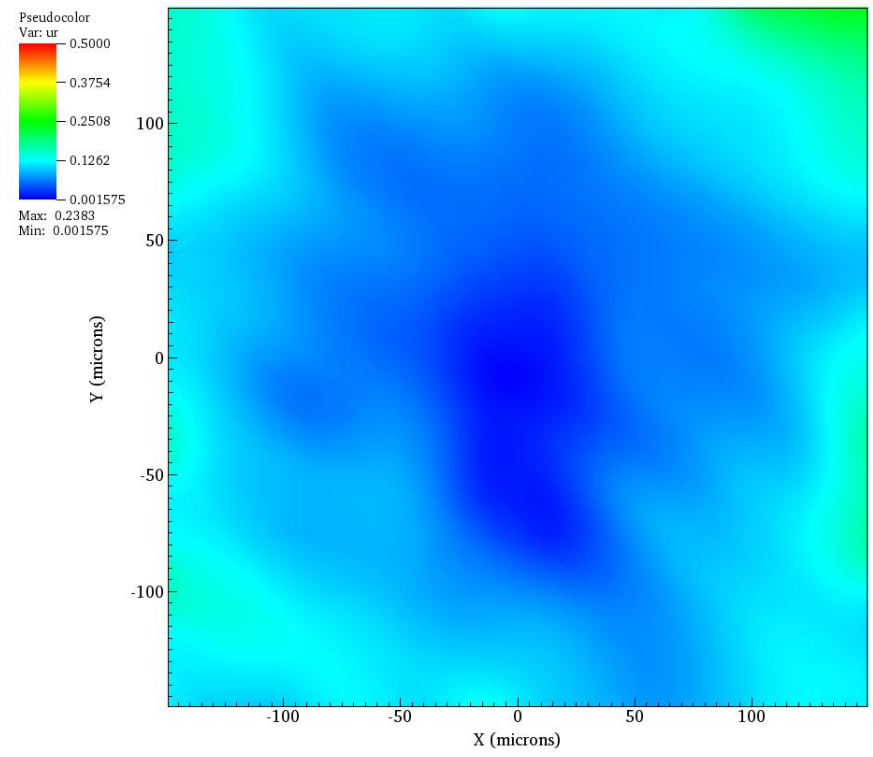

Figure 24. Bare silicon wafer radial displacements at $100^{\circ} \mathrm{C}$. 


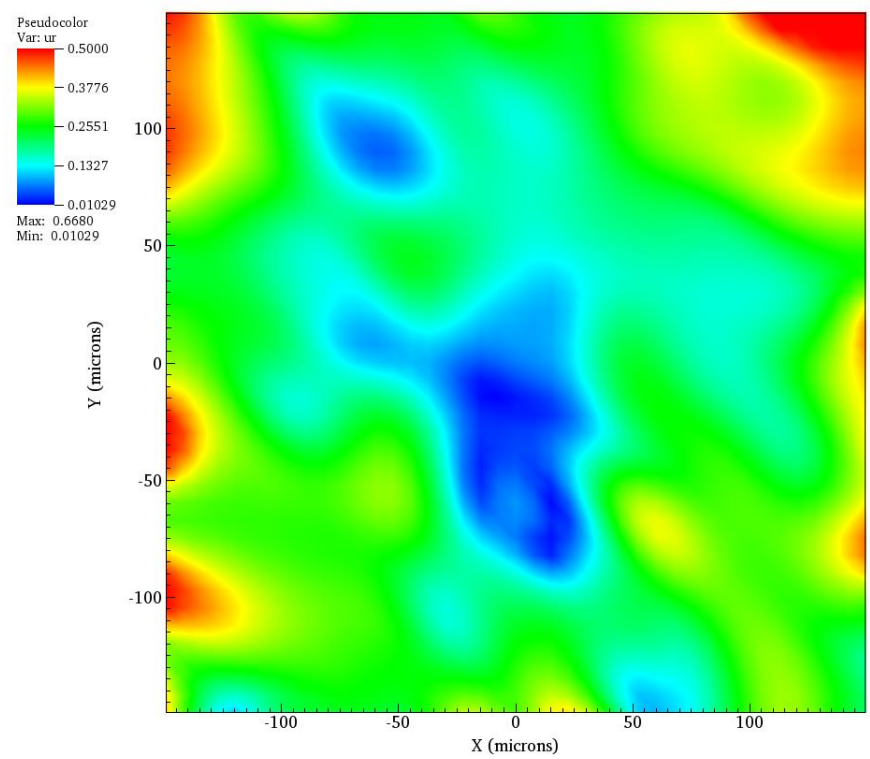

Figure 25. Bare silicon wafer radial displacements at $200^{\circ} \mathrm{C}$.

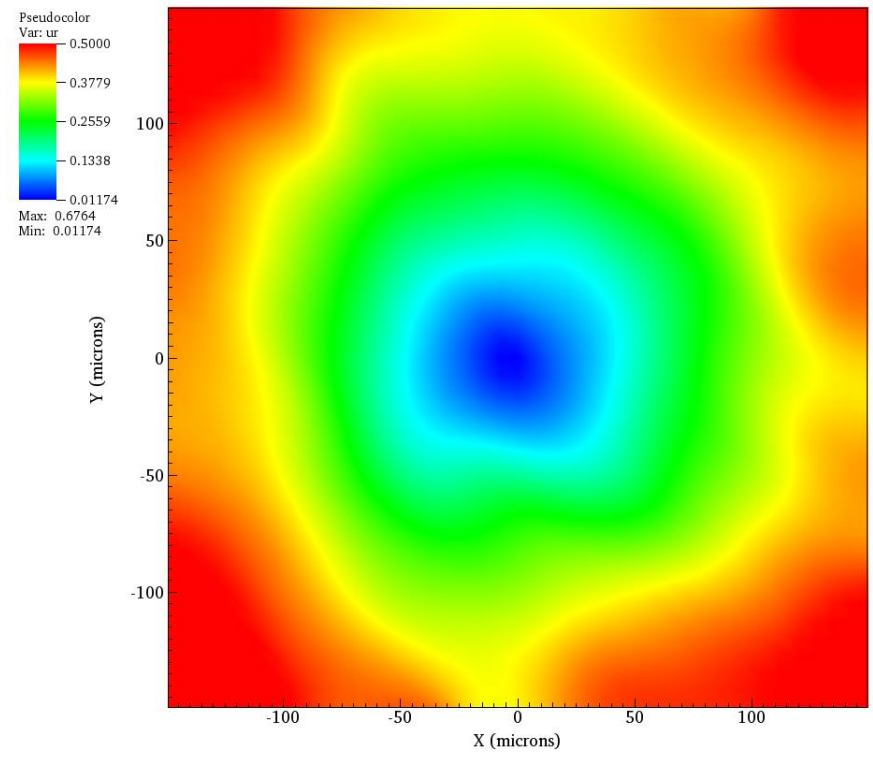

Figure 26. Bare silicon wafer radial displacements at $300^{\circ} \mathrm{C}$. 


\section{F. ELLIPSOMETRY TESTING}

Ellipsometery testing was accomplished with a J.A. Woollam WVASE32 ellipsometer, which allowed for thickness characterization of the PZT thin films with an unknown index of refraction and is shown in Figure 27.

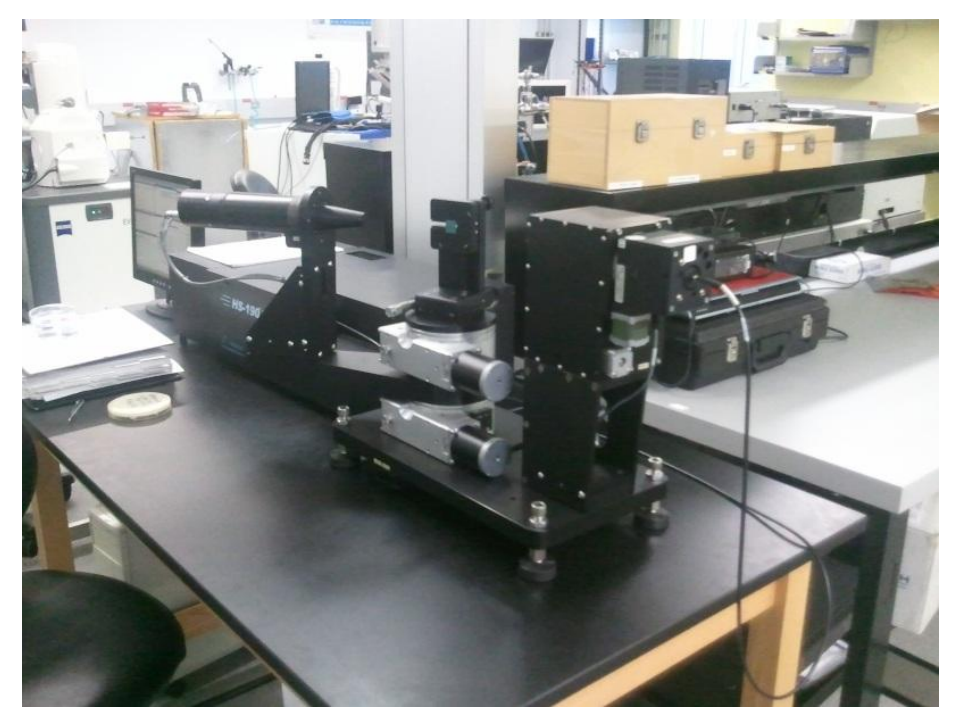

Figure 27. J.A Woollam WVASE32 ellipsometer.

To calculate the index of refraction for the previously uncharacterized PZT sol gels, multiple angles ranging from 65 to 75 degrees in 5 degree increments were analyzed via the WVASE32 interface. Once the index of refraction was calculated for each unknown PZT sol gel sample, the thickness was measured using a fixed 75 degree angle. 


\section{RESULTS AND DISCUSSION}

In the following sections, the error present in the system, thermally developed strains, estimated film failure criteria, and film cracking response of the PZT sol gel system are discussed. Table 9 lists the initial thicknesses for each component analyzed which applies to both the poorly and well adhered film systems.

\begin{tabular}{|l|c|}
\hline Component & Thickness (nanometers) \\
\hline Silicon dioxide & 100.5 \\
\hline 3-layer PZT & 43.3 \\
\hline 12-layer PZT & 101.4 \\
\hline
\end{tabular}

Table 9. Initial thicknesses of system components.

\section{A. ERROR QUANTIFICATION}

Full field images were cropped from $2048 \times 2048$ pixels down to $680 \times 840$ to eliminate any error based on objective distortion at the edges of the images. However, noise was still prevalent in the measurement system. The Leica MST49 was housed on a vibration dampening table, but prior to future research at a higher resolution, additional vibration dampening methods need to be explored. Much of the noise present in the system can likely be attributed to the $x$ and $y$ translational capabilities of the microscope stage.

In an effort to quantify the noise present in the system based on the $x$ and $y$ translations of the table and stage combination, sets of images were acquired over a 60 second period. The time elapsed noise in the $x$ and $y$ directions are shown in Figure 28 and Figure 29. The average noise present in the system is approximately (1/5) pixels.

Based on the displacements encountered during thermal loading, the percent error encountered at displacements associated with lower temperatures is approximately $5.1 \%$. The percent error encountered at displacements associated with higher temperatures near 
the region of interest drops to approximately $0.58 \%$. It is important to note that this baseline error is simply a rigid body translation and should not affect the strain measurements.

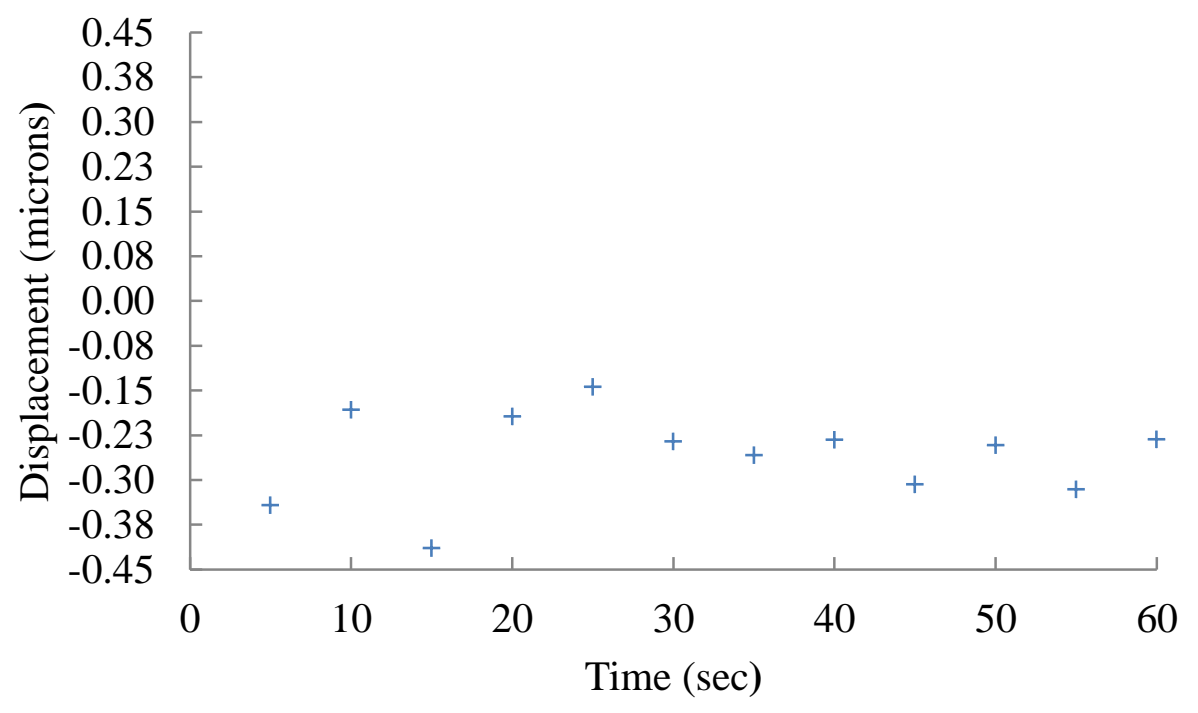

Figure 28. Steady state $x$ displacements for 60 seconds.

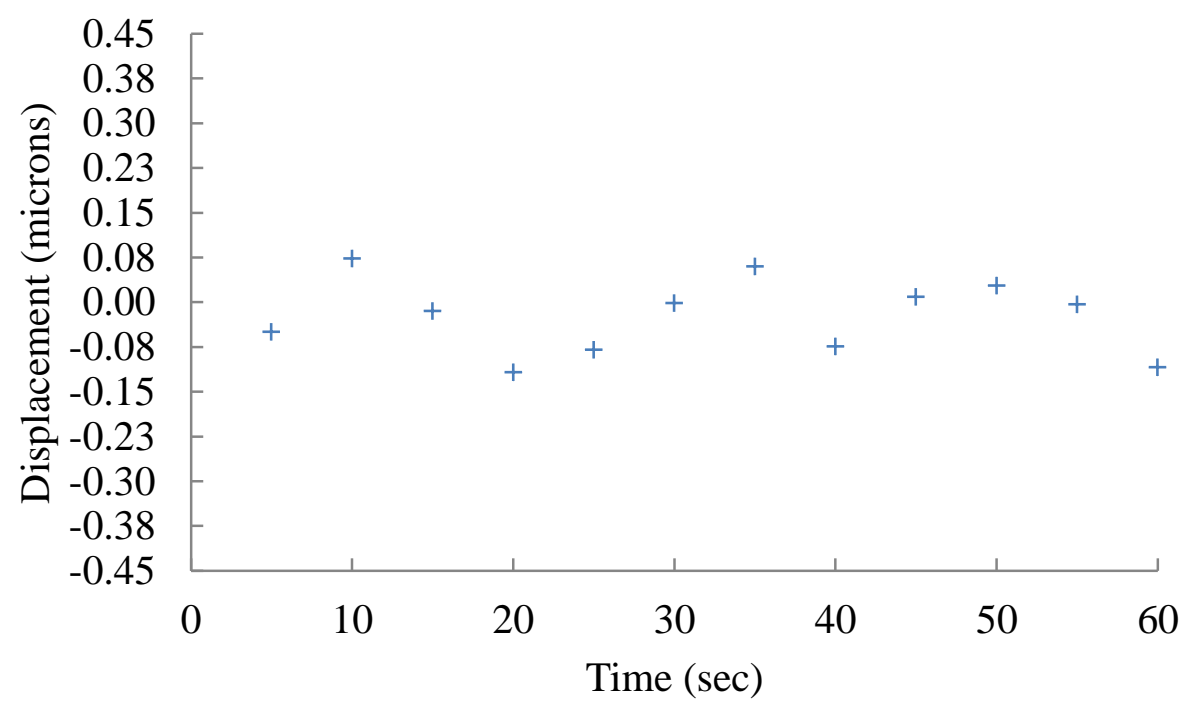

Figure 29. Steady state $y$ displacements for 60 seconds. 


\section{B. THERMAL STRAIN DEVELOPMENT AND FILM CRACKING BEHAVIOR OF POORLY ADHERED FILMS}

Film failure was analyzed for each sol gel solution for both 3 and 12 layer systems. The thermally developed strains and island densification was explored for a temperature range from ambient to $300^{\circ} \mathrm{C}$.

\section{i. 3-LAYER FILMS}

The 3-layer PZT poorly adhered films failed at an average temperature of $76.6^{\circ} \mathrm{C}$, a corresponding strain of $6.17 \times 10^{-4}$, and an average island size of $7,263 \mu \mathrm{m}^{2}$. Figure 30 through Figure 39 show the initial cracking response of the 3-layer poorly adhered films, the island densification as heat is added, and the sub-cracking of the initial islands formed during film failure.

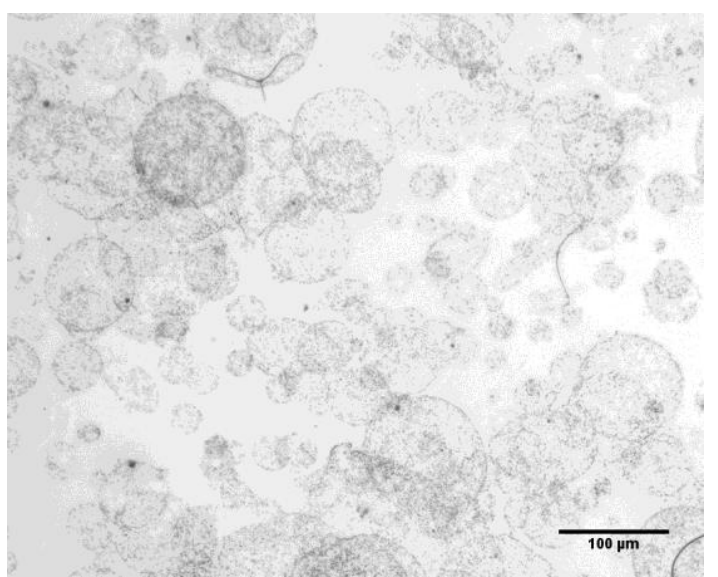

Figure 30. 3-layer initial cracking response.

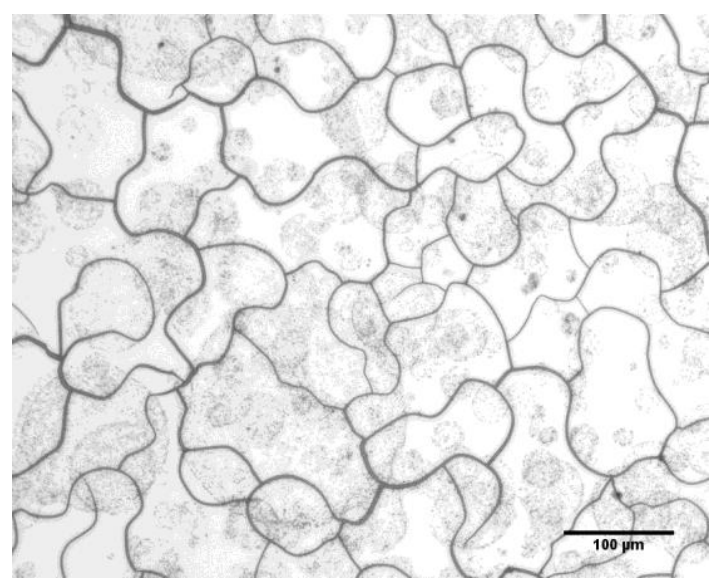

Figure 31. 3-layer cracking response at $100^{\circ} \mathrm{C}$. 


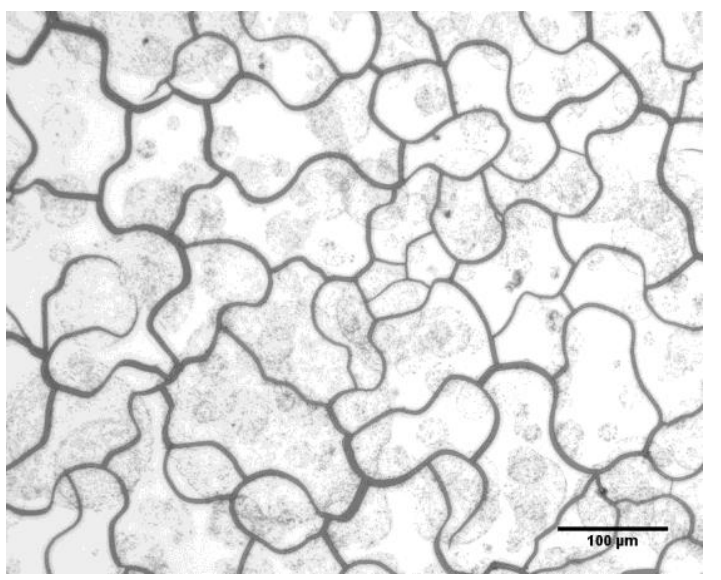

Figure 32. 3-layer cracking response at $125^{\circ} \mathrm{C}$.

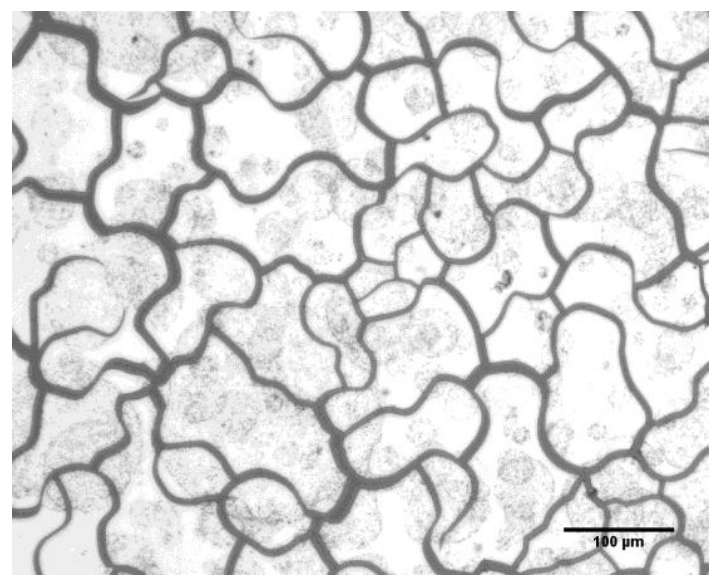

Figure 34. 3-layer cracking response at $175^{\circ} \mathrm{C}$.

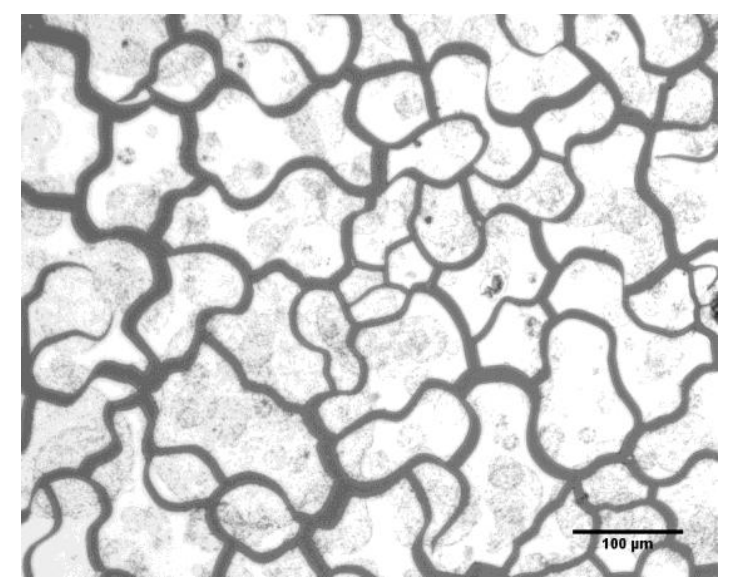

Figure 36. 3-layer cracking response at $225^{\circ} \mathrm{C}$.

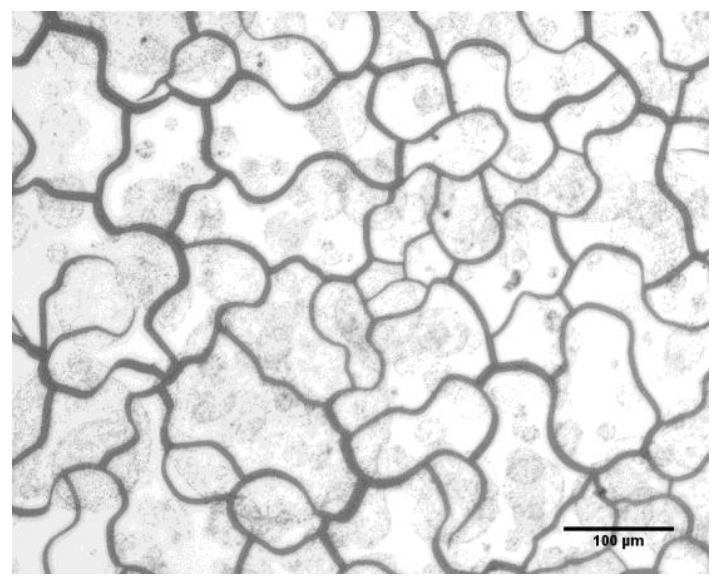

Figure 33. 3-layer cracking response at $150^{\circ} \mathrm{C}$

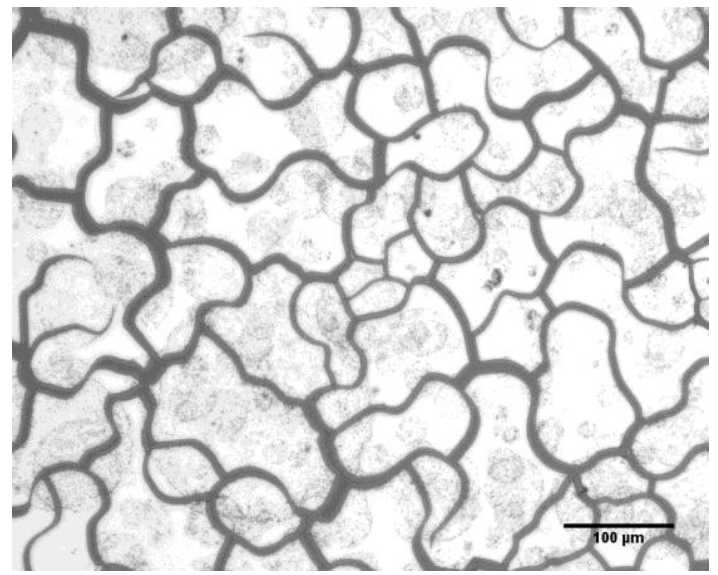

Figure 35. 3-layer cracking response at $200^{\circ} \mathrm{C}$.

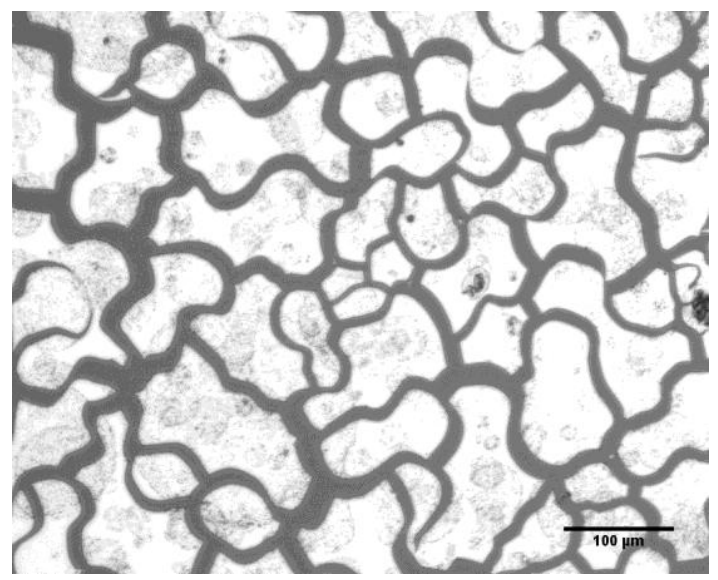

Figure 37. 3-layer cracking response at $250^{\circ} \mathrm{C}$ 


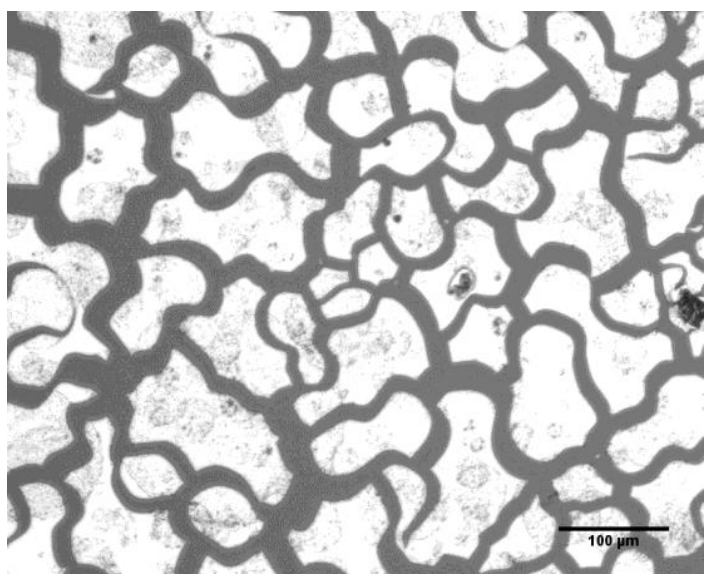

Figure 38. 3-layer cracking response at $275^{\circ} \mathrm{C}$.

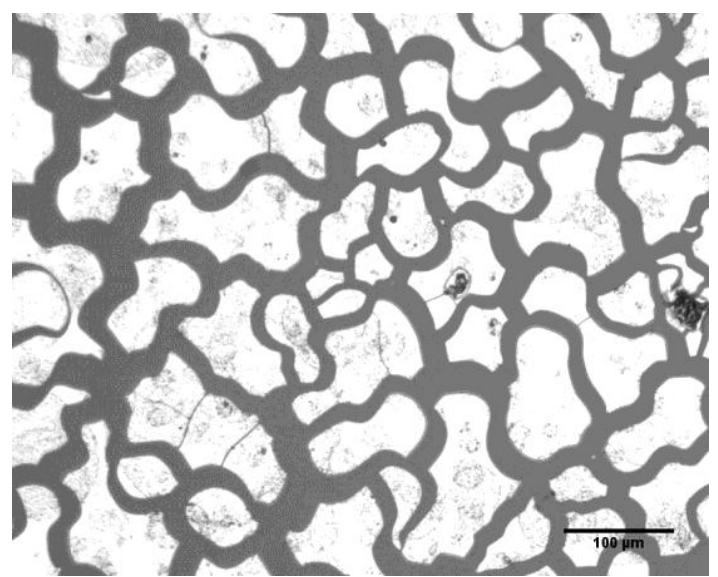

Figure 39. 3-layer cracking response at $300^{\circ} \mathrm{C}$

\section{ii. 12-LAYER FILMS}

The 12-layer PZT poorly adhered films failed at an average temperature of $78.1^{\circ} \mathrm{C}$, a corresponding strain of $-1.83 \times 10^{-4}$, and an average island size of $18,692 \mu \mathrm{m}^{2}$. Figure 40 through Figure 49 show the initial cracking response of the 12-layer poorly adhered films, the island densification as heat is added, and the sub-cracking of the initial islands formed during film failure.

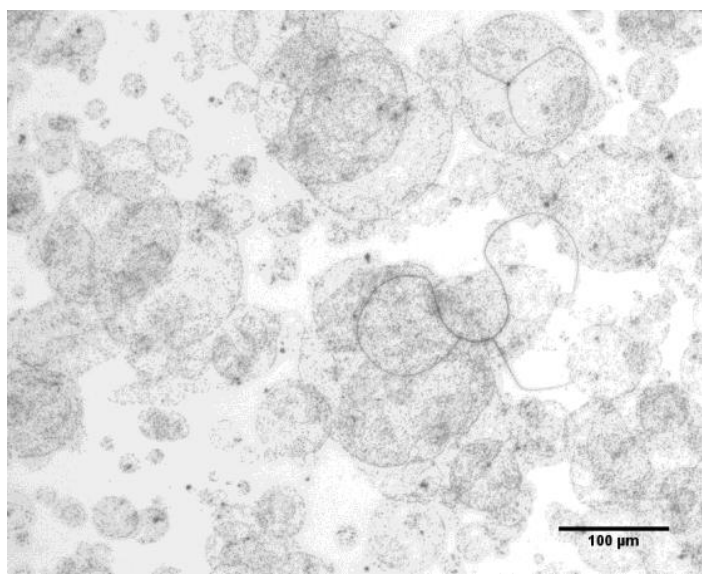

Figure 40. 12-layer initial cracking response.

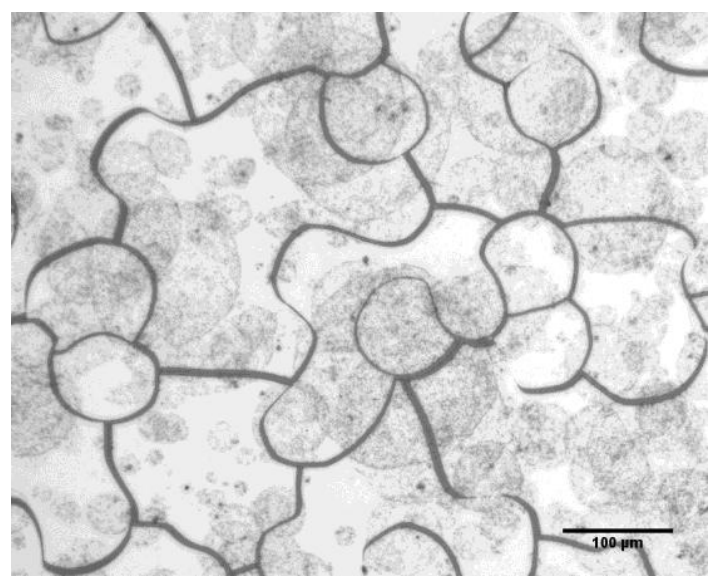

Figure 41. 12-layer cracking response at $100^{\circ} \mathrm{C}$ 


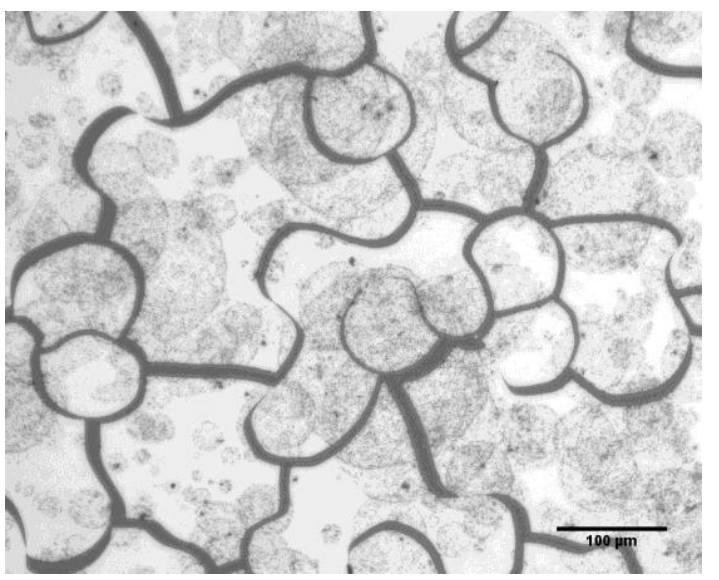

Figure 42. 12-layer cracking response at $125^{\circ} \mathrm{C}$.

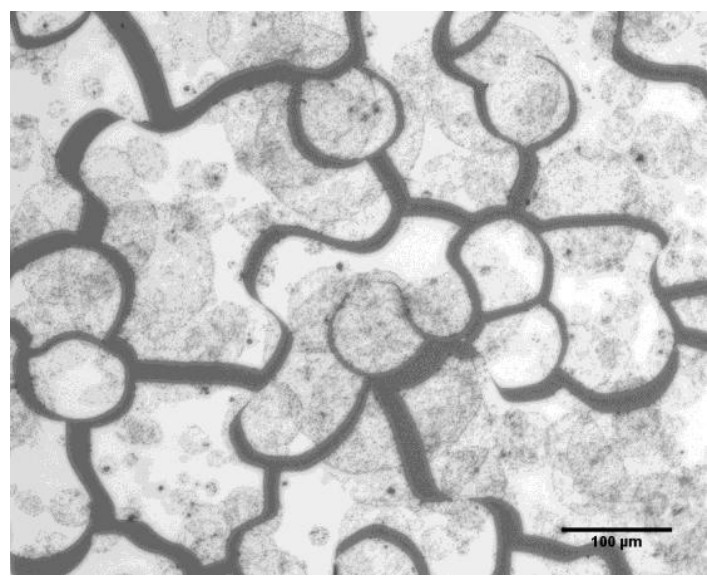

Figure 44. 12-layer cracking response at $175^{\circ} \mathrm{C}$.

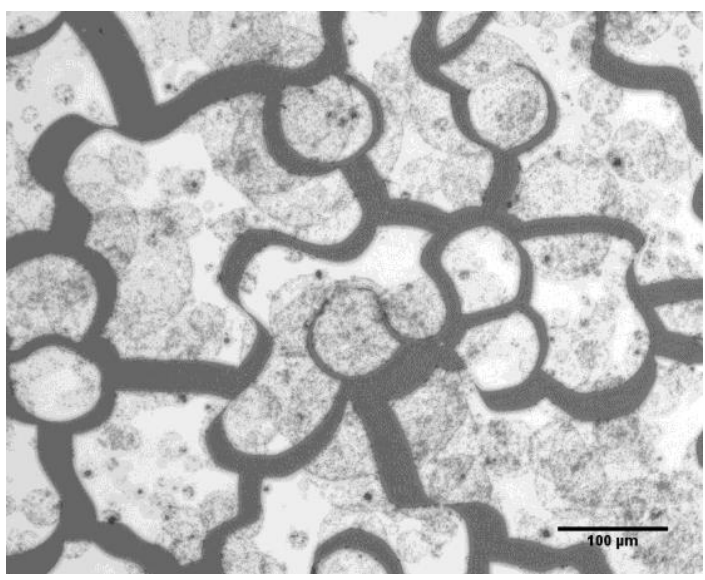

Figure 46. 12-layer cracking response at $225^{\circ} \mathrm{C}$.

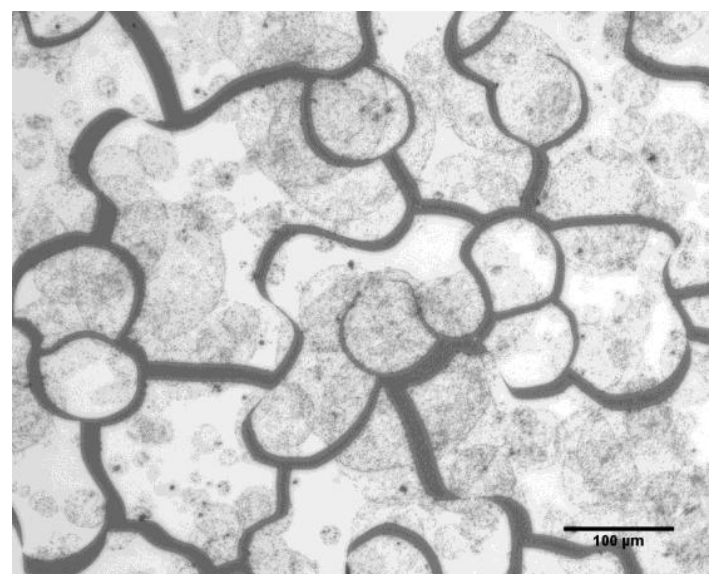

Figure 43. 12-layer cracking response at $150^{\circ} \mathrm{C}$

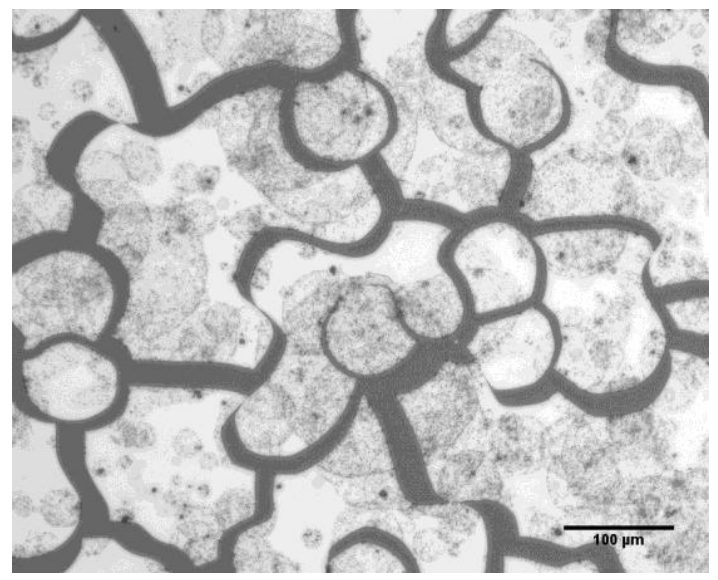

Figure 45. 12-layer cracking response at $200^{\circ} \mathrm{C}$.

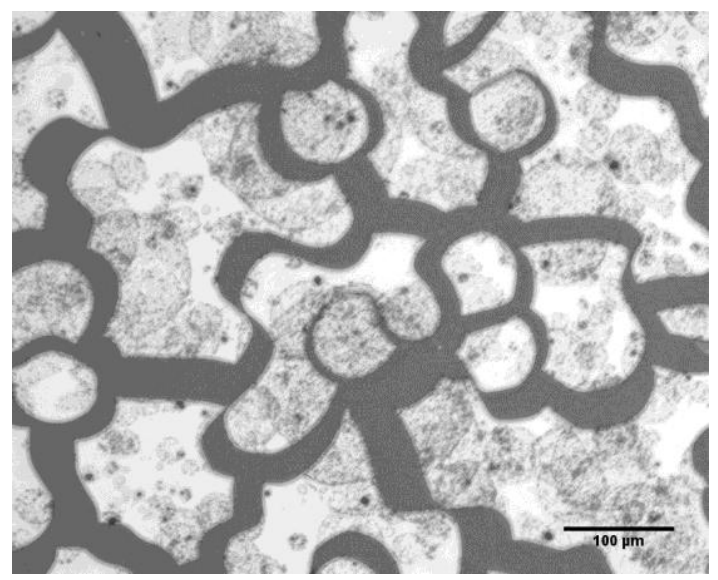

Figure 47. 12-layer cracking response at $250^{\circ} \mathrm{C}$. 


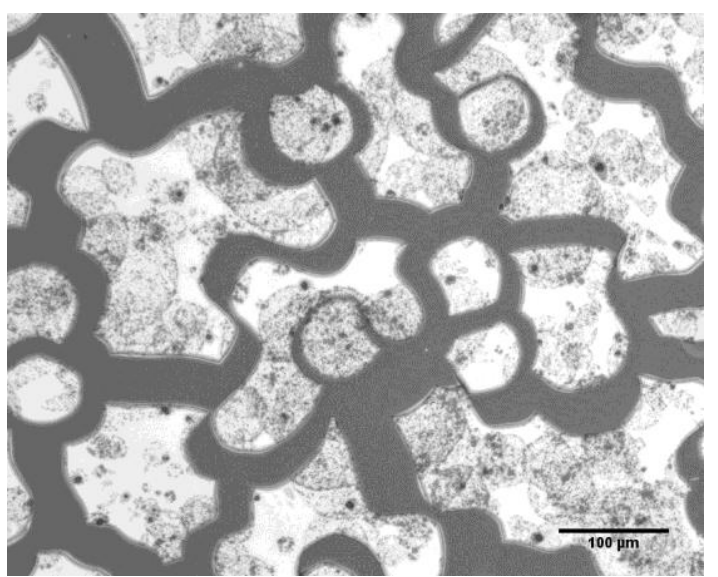

Figure 48. 12-layer cracking response at $275^{\circ} \mathrm{C}$.

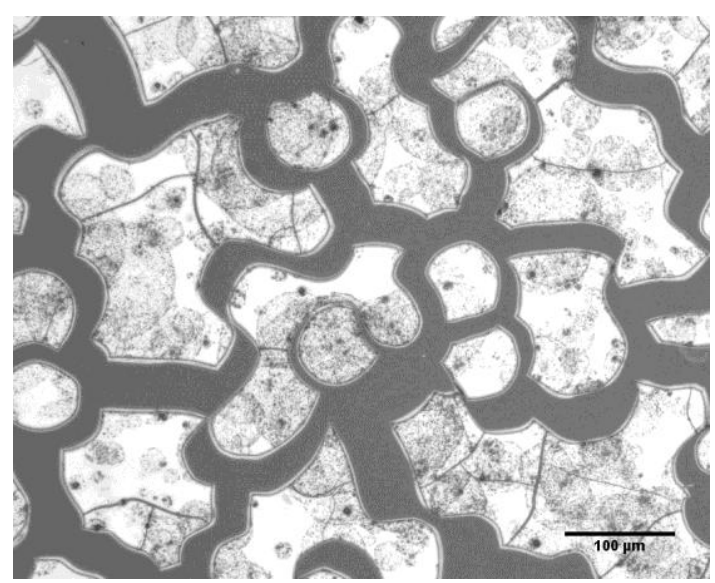

Figure 49. 12-layer cracking response at $300^{\circ} \mathrm{C}$

\section{PREDICTIONS OF CRACK INITIATION IN POORLY ADHERED FILMS}

The surface failure strains associated with the 3-layer and 12-layer poorly adhered systems are not easily relatable as indicated by Figure 50. Four samples were tested for both the 3-layer and 12-layer film systems with an average standard of deviation of $2.19 \times 10^{-4}$ for the 3 -layer films and $5.32 \times 10^{-4}$ for the 12-layer films.

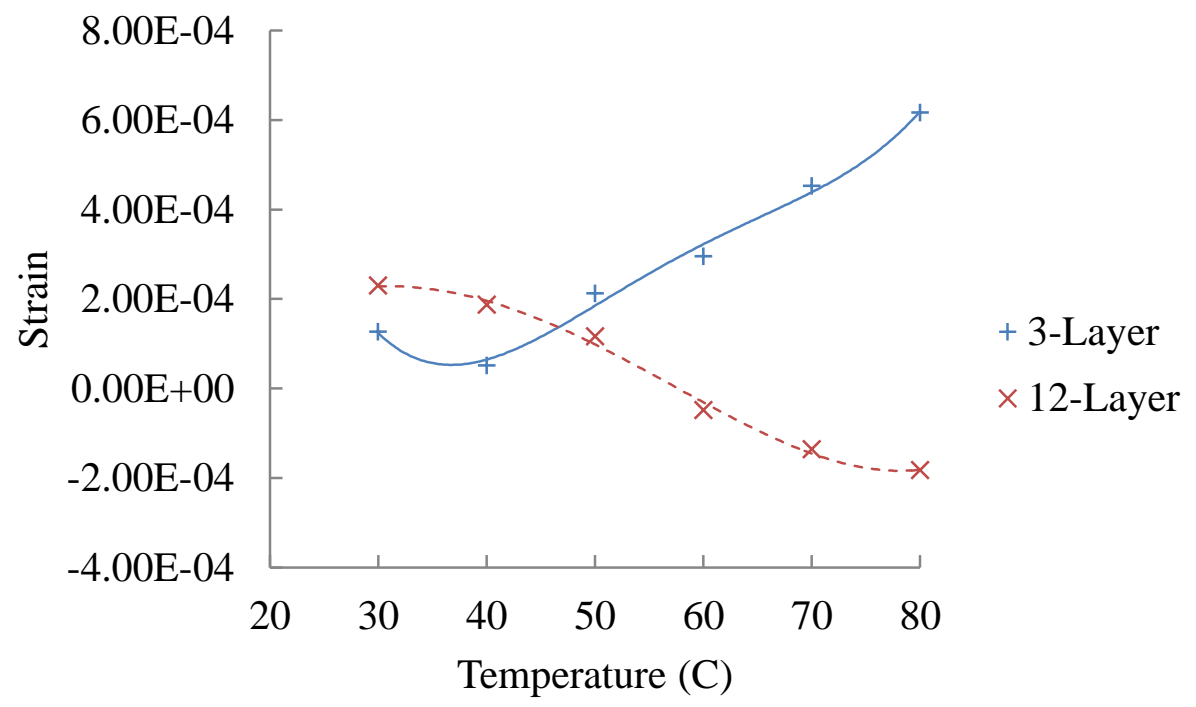

Figure 50. Thermal strain development in poorly adhered films. 
The temperature associated with film failure for both the 3-layer and 12-layer films were within $2 \%$ of each other but the strains associated with these temperatures vary significantly. The results indicate that the 3-layer films failed in tension at the surface whereas the 12-layer films failed in compression at the surface.

Due to the rapid changes of the index of refraction of the PZT films, ellipsometry measurements were unable to be collected during thermal loading. Ellipsometry measurements were taken once the sample had been thermally loaded and the index of refraction could be recalculated. The post $300^{\circ} \mathrm{C}$ heating ellipsometry measurements indicate that the 3-layer films decrease in thickness by approximately $39.3 \%$ and the 12 layer films decrease by approximately $73.8 \%$.

This significant thickness change in the 12-layer films helps to explain the drastically different results from the 3-layer films. Since DIC is a surface measurement technique and can only capture the strain field at the surface of the film, as the films become thicker and more complex, the mechanics also become increasing more complex and harder to effectively measure. Both residual (as deposited) stress levels which could be very high and tensile, and potential variations in the load through the thickness (strain gradient) could factor into these observed results.

What was effectively happening was that each of the film systems were capturing a different part of the thermomechanical loading that was occurring. The 3-layer films contained less solvent for densification; therefore, the tensile strains from linear expansion of the silicon dioxide wafer were more dominant in the DIC results. The 12layer films contain a greater amount of solvent; therefore, the rapid densification of the films and the resulting shrinkage stresses were more dominant in the DIC results from the 
top surface. The added thickness also allows for the drying gel to essentially mask the thermal expansion that is taking place at the film-substrate interface during the initial heating state because the gel is not a rigid body at this point. Due to the lack of a thickness measurement across the heating range, additional tests shall be conducted prior to drawing any further conclusions in 12-layer films.

The islands that developed in the 12-layer films were approximately $61.1 \%$ larger than those of the 3-layer films. To quantify island densification, 4 islands were selected at random for the 3-layer films with and average standard of deviation of $973.48 \mu \mathrm{m}^{2}$ and 3 islands were selected for the 12-layer films with and average standard of deviation of $3,074.64 \mu \mathrm{m}^{2}$. The area was measured and recorded from island formation to a maximum temperature of $300^{\circ} \mathrm{C}$. The island densification follows a relatively linear pattern as shown in Figure 51.

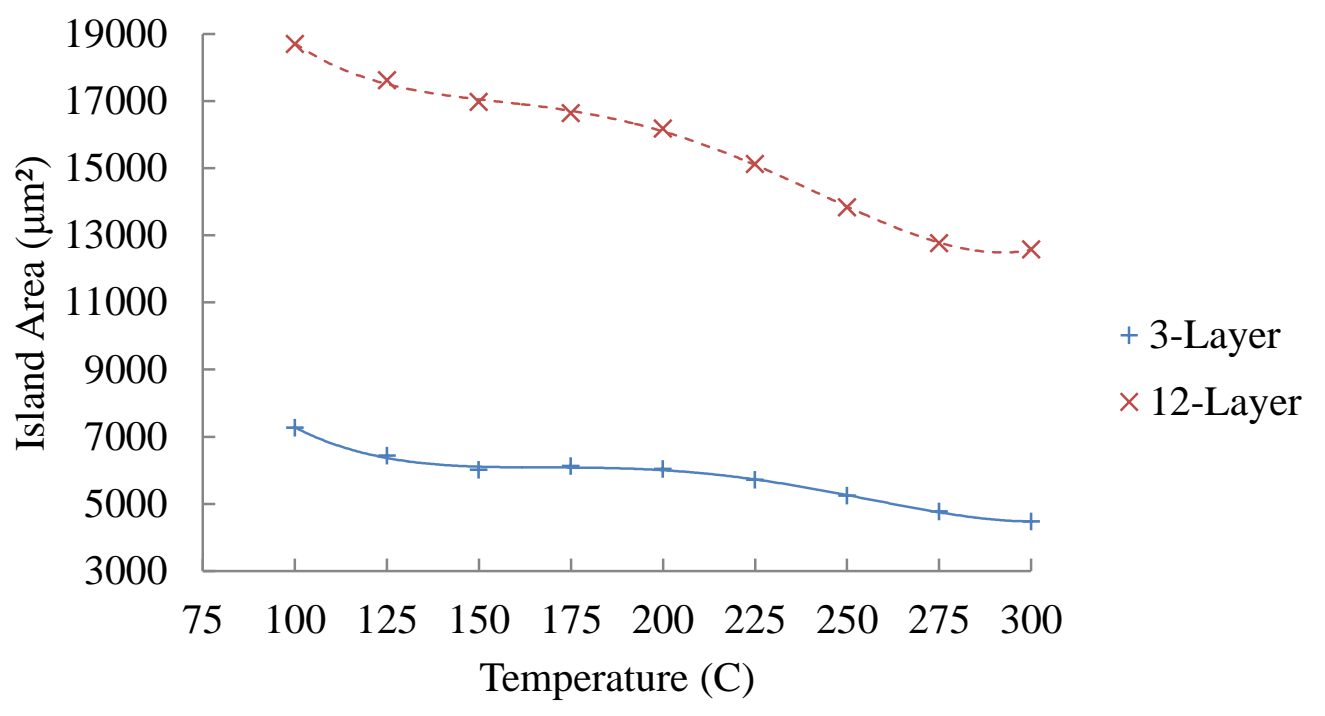

Figure 51. Island densification in poorly adhered films. 
The islands formed in the 3-layer samples reduced in area by approximately $38 \%$ and the 12-layer samples reduced in area by approximately $33 \%$. Once the initial islands approached the approximate a 30\% area reduction, sub-cracking began and formed a series of new, smaller islands. At this point, the newly formed islands continued to contract as additional heat was added.

\section{THERMAL STRAIN DEVELOPMENT IN WELL ADHERED FILMS}

The thermally developed strains were explored for a temperature range from ambient to $300^{\circ} \mathrm{C}$. Three samples were tested for the 3-layer and five samples were tested for the 12-layer film systems with an average standard of deviation of $5.98 \times 10^{-4}$ for the 3-layer films and $2.61 \times 10^{-3}$ for the 12-layer films.

The 3-layer and 12-layer well adhered films followed very similar strain development trends over the loading range. The initial strain in the 12-layer films is approximately $69.4 \%$ greater than the 3 -layer films and the strain corresponding to $300^{\circ} \mathrm{C}$ is $28.9 \%$ greater. Around the $200^{\circ} \mathrm{C}$ mark, there is an apparent change in the mechanical properties of the PZT films noted by the marked reduction in strain. The peak 3-layer and 12-layer strains associated with this point are $1.05 \times 10^{-3}$ and $2.72 \times 10^{-3}$ indicating a $61.4 \%$ greater peak strain development in the 12-layer films.

In comparison to the poorly adhered films at $50^{\circ} \mathrm{C}$ and $75^{\circ} \mathrm{C}$, the well adhered 3 layer film strain associated with these temperatures is an average of $75.3 \%$ less. The well adhered 12-layer film strain associated with these temperatures is an average of $23.1 \%$ greater. However, the peak thermal strain development is approximately $41.2 \%$ greater in well adhered vs. poorly adhered 3-layer PZT films. Additional testing of 12-layer 
poorly adhered films is necessary prior to any further comparisons of the peak strain development in 12-layer films.

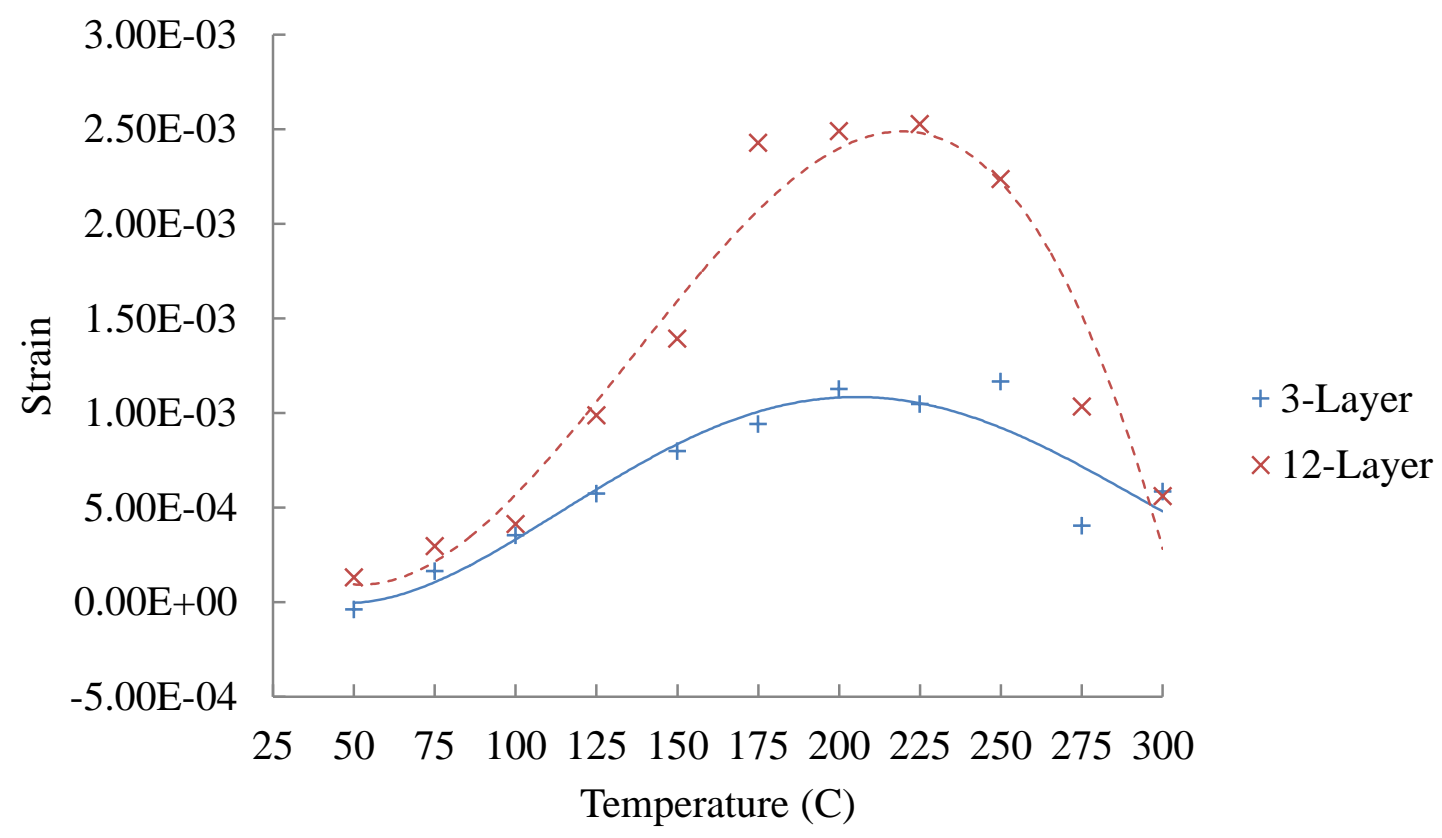

Figure 52. Thermal strain development in well adhered films.

Due to the rapidly changing optical properties of the PZT films, the thermal strain development is also presented over a reduced range from ambient to $225^{\circ} \mathrm{C}$. Around the same $200^{\circ} \mathrm{C}$ temperature mark, an apparent change in the mechanical properties occurred. The optical properties also changed significantly and rapidly, which made it difficult to limit the exposure of the camera while also maintaining significant light for the speckle pattern to be clearly visible for correlation. In this region the correlation coefficient increased on average by an order of magnitude. This significant change in the correlation coefficient indicates the onset of pyrolysis. The thermal strain development in well adhered films over the reduced range is shown in Figure 53. 


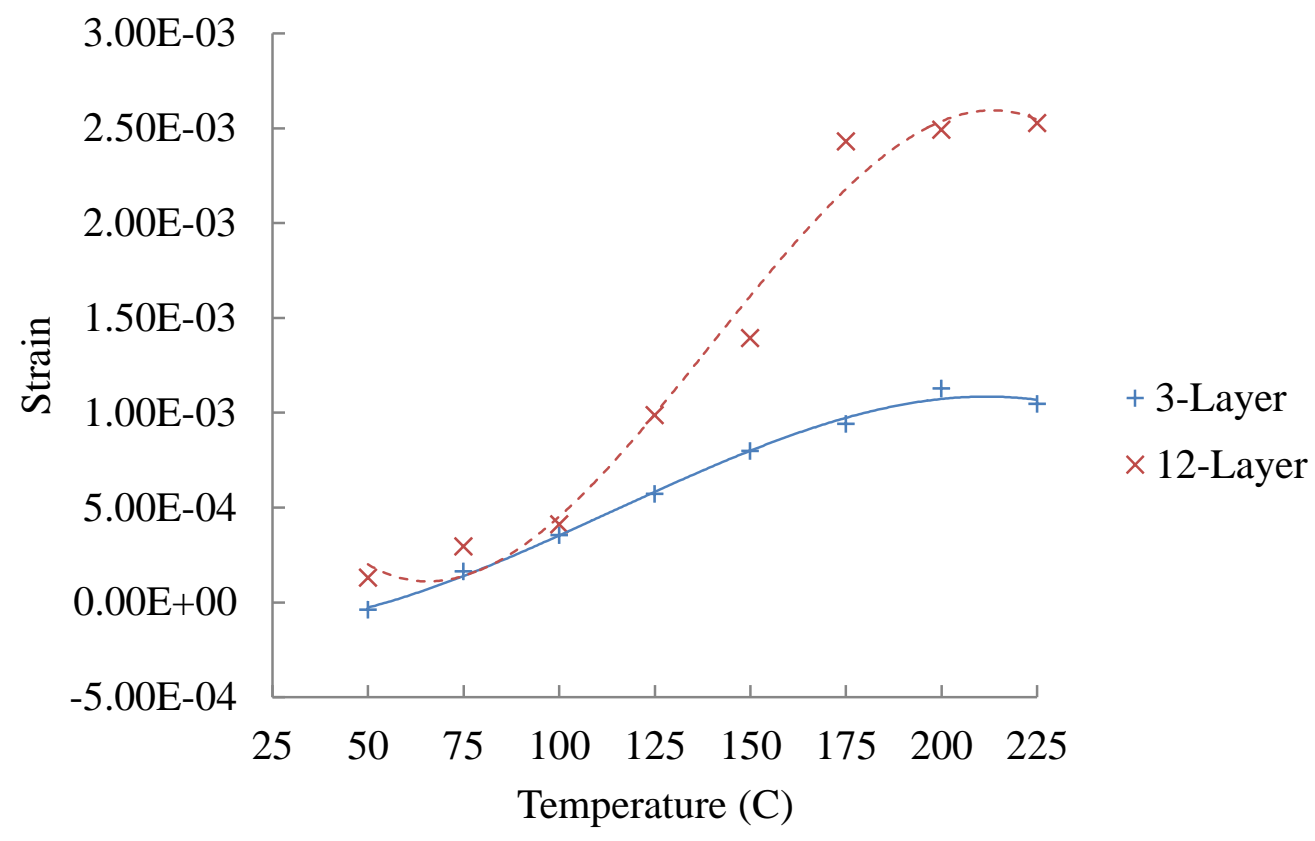

Figure 53. Thermal strain development in well adhered films over reduced range.

\section{i. 3-LAYER FILMS}

Radial displacement plots for the 3-layer films are presented to provide a graphical representation of the thermal loading. The 3-layer film radial displacements follow a similar trend to those of the silicon wafer thermal expansion radial displacements as shown previously. This is to be expected since the dominant mechanism of the thermal strain development in the 3-layer films is the tensile strain developed by the thermal expansion of the silicon wafer substrate. 


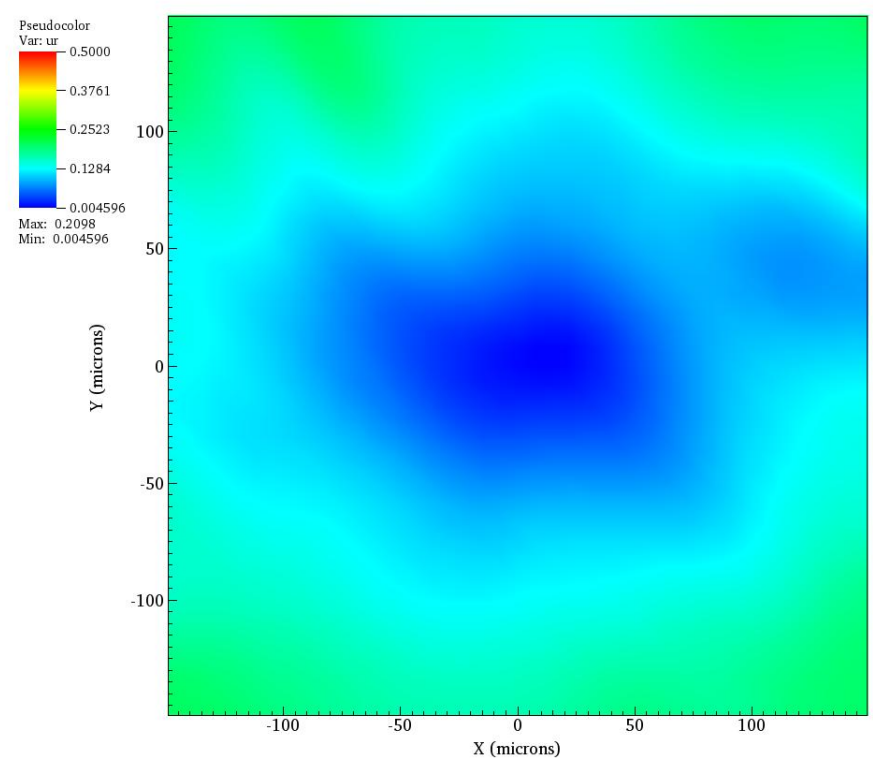

Figure 54. 3-layer radial displacements at $100^{\circ} \mathrm{C}$.

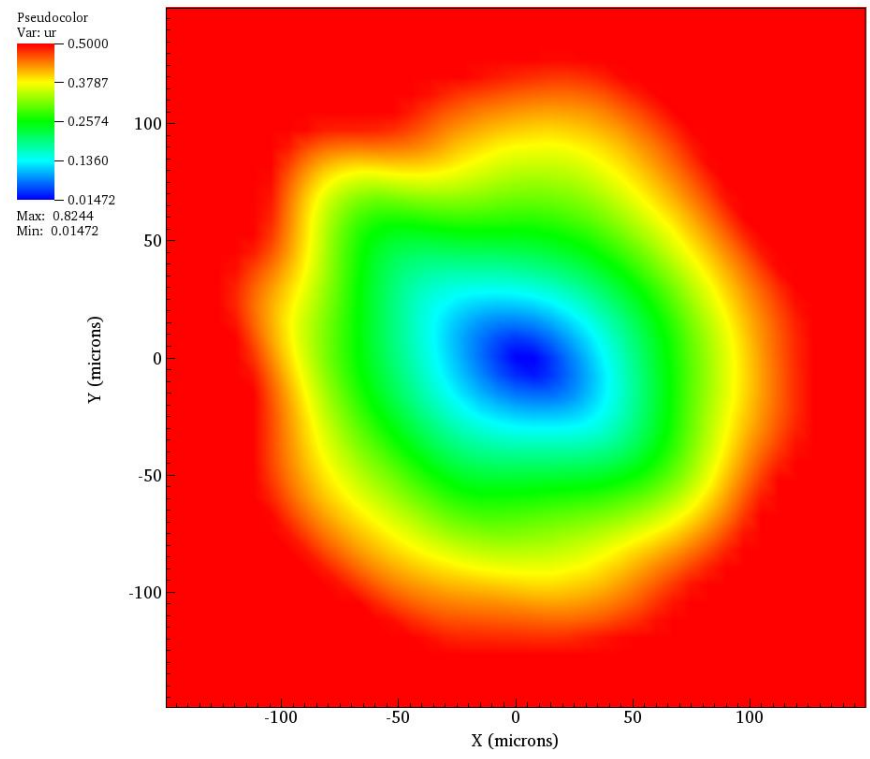

Figure 55. 3-layer radial displacements at $200^{\circ} \mathrm{C}$. 


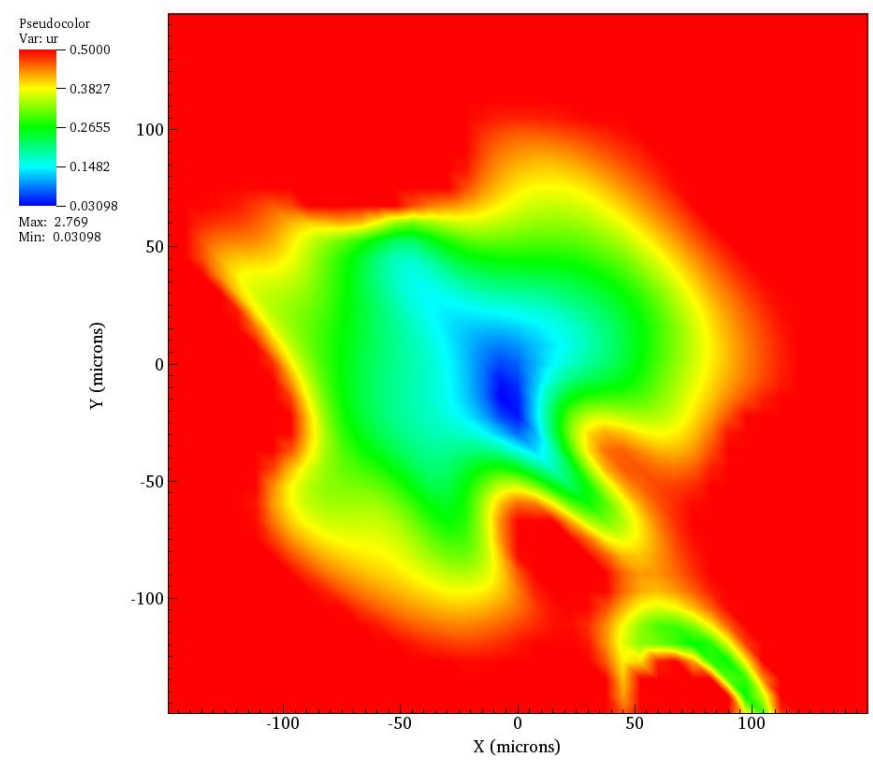

Figure 56. 3-layer radial displacements at $300^{\circ} \mathrm{C}$.

\section{ii. 12-LAYER FILMS}

Where the radial displacements in the 3-layer films follow an apparent linear, uniform trend, the 12-layer films exhibit a less distinguishable trend. The 12-layer films exhibit more localized displacement states without an easily distinguishable uniform, linear trend; therefore 12-layer radial displacement plots were omitted.

\section{E. RESULTS SUMMARY}

The 3-layer and 12-layer poorly adhered films failed at temperatures within $2 \%$ percent of each other despite varying surface strain fields, indicating that the strain magnitude at the interface drives film failure. The peak thermally developed strain is 41.2\% greater in well adhered 3-layer films compared to poorly adhered films. This indicates that adhesion largely dictates film failure since it would be expected that the failure strains in the poorly adhered films would exceed those present in the well adhered films. 


\section{CONCLUSIONS}

The following conclusions can be drawn from the results presented in this thesis. First, DIC is an effective means for measuring thermally developed strains in both well and poorly adhered PZT thin films. An airbrushed nanoparticle speckle allows for accurate measurement of poorly adhered films without inhibiting crack development and growth.

Second, poorly adhered 3-layer and 12-layer PZT thin films fail at temperatures within $2 \%$ of each other but fail under contrasting surface strain fields. This indicates that film failure is driven by the strain at the interface. Third, initial islands formed during failure of 3-layer films were $61.1 \%$ smaller in area than those formed during initial failure of 12-layer films. Initial islands formed reduced in area by approximately $30 \%$, at which time sub-cracking occurred.

Fourth, a significant mechanical and optical property change occurs in PZT films from $200^{\circ} \mathrm{C}$ to $225^{\circ} \mathrm{C}$. The peak strains occur at this point with the 12 -layer peak strain $61.4 \%$ greater than the peak 3-layer strain. Finally, the thermal strain development is approximately $41.2 \%$ greater in well adhered vs. poorly adhered 3-layer PZT films, indicating that adhesion largely dictates film failure. Additional testing of 12-layer poorly adhered films is necessary prior to any further conclusions. 


\section{RECOMMENDATIONS FOR FUTURE WORK}

This thesis laid the ground work for future research into the material properties of PZT thin films. However, there are still additional tests to be conducted for a complete mechanical property estimation of PZT sol gels. It would be beneficial to conduct research on the film thickness variations that occur over the entire heating range to allow for additional characterization of what is occurring in 12-layer films. The addition of wafer curvature testing during thermal loading would also allow for the elastic modulus and Poisson's ratio of the utilized PZT sol gel to be estimated for use in theoretical design calculations.

It would also prove beneficial to characterize additional PZT sol gel recipes as well as the effects of various chemical additions. Additional recipes were briefly explored in conjunction with this thesis as well as the results of omitting components to modify the cracking response of PZT sol gels. It has been shown that omitting glycerol, ethylene glycol, and lactic acid from the solution results in films that fail at

approximately $30^{\circ} \mathrm{C}$ with $2560 \mu \mathrm{m}^{2}$ island sizes. It has also been shown that only omitting glycerol and lactic acid results in films that fail at approximately $90^{\circ} \mathrm{C}$ with initial island sizes that exceeded the 10x objective. 


\section{LIST OF REFERENCES}

Berfield, T., Patel, J., Shimmin, R., Braun, P., Lambros, J., Sottos, N. 2007. Micro- and nanoscale deformation measurement of surface and internal plans via digital image correlation. Experimental Mechanics 47:51-62.

Beuth, J. 1992. Cracking of thin bonded films in residual tension. Int. J. Solids Structures 29:1657-1675.

Bhusan, B. 2004. Handbook of Nano-technology. NewYork: Springer-Verlag Berlin Heidelberg.

Dally, J., William, R. 2005. Experimental Stress Analysis. Knoxville: College House Enterprises, LLC.

Hutchinson, J., Suo, Z. 1992. Mixed mode cracking in layered materials. Advances in Applied Mechanics 29:126-137.

Lee, W., Routh, A. 2004. Why do drying films crack? Langmuir 20:9885-9888.

Nakasa, K., Takata, S., and Hirozo, I. 1998. An analysis of island-delamination type cracking pattern in the brittle film coated on a disk under axisymmetric tension. Engineering Fracture Mechanics 59:191-202.

Pan, B., Qian, K., Xie, H., and Asundi, A. 2009. Two-dimensional digital image Correlation for in-plane displacement and strain measurement: a review. Measurement Science and Technology 20:1-17.

Tirumkudulu, M., Russel, W. 2004. Role of capillary stresses in film formation. Langmuir 20:2947-2961.

Mach, K., Nelson, D., Denny, Mark. 2007. Techniques for predicting the lifetimes of wave-swept macroalgae: a primer on fracture mechanics and crack growth. The Journal of Experimental Biology 210:2213-2230.

Xia, C., Hutchinson, J. 2000. Crack patterns in thin films. Journal of the Mechanics and Physical Solids 48:1107-1131.

Yi, G., Sayer, M. 1996. An acetic acid/water based sol-gel PZT process I: modification of $\mathrm{Zr}$ and Ti alkoxides with acetic acid. Journal of Sol-Gel Science and Technology 6:65-74.

Yow, H., Goikoetxea, M., Goehring, L., Routh, A. 2010. Effect of film thickness and particle size on cracking stresses in drying latex films. Journal of Colloid and Interface Science 352:542-548. 
Zhang, S., Sun, D., Fu, Y., Du, H. 2005. Toughness measurement of thin films: a critical review. Surface and Coatings Technology 198:74-84.

Zhao, M., Fu, R., Lu, D., Zhang, T. 2002. Critical thickness cracking of $\mathrm{Pb}\left(\mathrm{Zr}_{0.53} \mathrm{Ti}_{0.47}\right) \mathrm{O}_{3}$ thin films deposited on Pt/Ti/Si/(100) substrates. Acta Materialia 50:4241-4254.

Zak, A., Williams, M., 1963. Crack point singularities at a biomaterial interface. Journal of Applied Mechanics 30:142-143. 